\title{
Spring habitats of small pelagic fish communities in the Bay of Biscay
}

\author{
Doray Mathieu ${ }^{1,{ }^{*}}$, Hervy Camille ${ }^{1}$, Huret Martin ${ }^{2}$, Petitgas Pierre ${ }^{1}$
}

${ }^{1}$ Unité Écologie et Modèles pour l'Halieutique, Centre Ifremer Atlantique, Rue de l'lle d'Yeu, BP 21105, 44300 Nantes Cedex 3, France

${ }^{2}$ Laboratoire de Biologie Halieutique, Centre Ifremer Bretagne, ZI de la Pointe du Diable, CS 10070, 29280 Plouzané, France

*Corresponding author : Mathieu Doray, email address : mathieu.doray@ifremer.fr

\begin{abstract}
:
Mapping habitats of species communities helps to inform on the ecological processes which drive their distribution. This information is critical to identify suitable areas for spatial management, aimed at preserving biodiversity, ecosystem functions or essential habitats. While demersal fish have been extensively studied at the community scale, small pelagic fish have mainly been characterised at the population scale. This paper presents a community-based approach on the biodiversity of small pelagic fish, with the aim to: (i) define small pelagic fish communities, (ii) characterise their spatial and interannual dynamics, and (iii) assess their habitats. We present a Multiple Factor Analysis (MFA)based method that characterises the spatio-temporal variability in a series of multivariate maps. The main components of variability in these maps are identified to define "characteristic areas" displaying contrasting conditions in both MFA ordination and geographical spaces. Characteristic habitats of fish communities were defined by the correlation between the main components of variability from MFAs applied to maps containing fish information on one hand, and on hydrographic variables on the other hand. The analysis of the long term PELGAS survey series of fish biomass and hydrological indices maps resulted in the characterisation of mesoscale latitudinal gradients and coarse to mesoscale onshore-offshore gradients in both fish and hydrology datasets. A community with anchovy (E. encrasicolus) and chub mackerel (S. colias) as indicator species was consistently distributed in southeast Biscay. This area was associated with higher bottom temperatures, which likely affected the fish community through physiological processes. A second community with small clupeiforms as indicator species was found in coastal spawning habitats. These habitats were typically characterised by low salinity, a probable proxy for high productivity and good feeding grounds for those species. Mapping the habitats of small pelagic fish communities may inform marine spatial management, aimed at preserving biodiversity, ecosystem structure and function. In addition, it may help in achieving maximum sustainable yields of these commercially important species, and contribute to achieving and maintaining good environmental status of shelf seas ecosystems.
\end{abstract}




\section{Highlights}

- A spatio-temporal approach of the diversity of small pelagic fish in their environment is proposed. Latitudinal and coastal-offshore spatial gradients identified in pelagic fish and hydrology. Anchovychub mackerel community consistently found in warmer southern spring habitat in Biscay. Small clupeiforms community found in coastal spring spawning habitats with low salinity in Biscay.

Keywords : Habitat, Small pelagic fish, Bay of Biscay, Spatial distribution, Multiple Factor Analysis 


\section{Introduction}

Spatial heterogeneity and patterns arise from the interplay of processes occurring at multiple scales and are functional properties of ecosystems (Legendre, 1993; Levin, 2000). At the single species level, variability in spatial distribution results from variability in biotic and abiotic environmental conditions, and internal

40 population behaviour (Petitgas et al., 2014). At the ecosystem level, biodiversity originates from the exploitation of heterogeneity in the environment, and through the evolutionary displacement of the way species utilize the environment (Levin, 2000).

Habitat can be defined as the environmental conditions that are favourable to an organism (e.g. for its presence, growth, Petitgas et al., 2014). In order to better understand the ecological processes driving the distribution of

45 organisms, habitat maps have been extensively produced by modelling the spatial distribution of organisms as a function of environmental conditions using statistical regression techniques (Guisan and Zimmermann, 2000; Le Pape et al., 2014). These habitat suitability maps of individual species have been used to identify and select suitable areas in marine spatial planning initiatives, such as Marine Protected Areas (MPAs) (Le Pape et al., 2014).

50 However, the same area often contains multiple species and their different life stages. Few studies have explicitly investigated this biotic control on individual species distribution stemming from the interactions of multiple co-occurent species (Georgescu et al., 2009). Moreover, with the advent of more holistic natural 
resources management approaches (e.g. Ecosystem Approach to Fisheries, Garcia et al., 2003; Ecosystem Integrated Assessment, Levin et al., 2009), the preservation of biodiversity, or of ecosystem processes such as 55 productivity, as well as habitats used by multiple rare or economically important species, are now included in marine management objectives (Whaley et al., 2007). Community-based modelling approaches (reviewed in Legendre and Legendre, 2012) may in this case be preferred to modelling of many species separately (Whaley et al., 2007).

For decades, ecologists have used multivariate methods (Legendre \& Legendre, 2012) to model the species

60 abundances recorded at sampling sites as a function of environment parameters, and to get insights on eventual interactions between species consistently found at the same location (competition, predation etc...) (Borcard et al., 1992; Legendre et al., 1997; Mueter and Norcross, 1999; Whaley et al., 2007; Georgescu et al., 2009). In marine ecology, long-term studies (>10 y) have shown that demersal or benthic fish assemblages with consistent composition can be persistently observed in the same place over significant time periods (e.g.

65 Gomes, 2001; Vaz et al., 2007). The analysis of the spatial and temporal dynamics of such demersal fish communities (sensu Fauth et al., 1996) has led to the definition of specific habitats, and provided important inputs for marine resource and human use spatial planning (Vaz et al., 2007).

Conversely, small pelagic fish spatial distributions have mainly been studied at the individual species level (e.g. Petitgas et al., 2014; Bertrand et al., 2016; Gastauer et al., 2016), or by comparing few dominant species, generally anchovy and sardine (e.g. Bertrand et al., 2004; Bonanno et al., 2014; Saraux et al., 2014). This is certainly due to the relatively lower number of small pelagic species in "wasp-waist" ecosystems (Cury et al., 2000), and to the classical dominance of a single species in upwelling areas (Fréon et al., 2005). Small pelagic fish are moreover more mobile and complete more frequent and larger migrations than demersal and benthic species, to cope with larger fluctuations of pelagic ecosystem hydrobiological conditions. The higher mobility

75 rate of pelagic fish reduces the odds of observing several species in the same habitats for long periods of time. However, persistent small pelagic fish communities have been identified in subtropical (Bonanno et al., 2015) or transition between subtropical and boreal (Certain et al., 2011) regions. The spatial distributions of small pelagic fish communities have been related to: i) concurrent environmental conditions, hence allowing to identify potential hydrobiological forcing conditions and habitats (Bonanno et al., 2015), and ii) top predators 80 distribution, to investigate predator-prey relationships (Certain et al., 2011).

In this paper, we propose a new community-based modelling approach to assess the multiscale spatial and 
temporal dynamics of the distributions of multiple species, eventually described by several biological traits. The methodology was applied to model the spatial and temporal distributions of small pelagic fish consistently observed in spring in the Bay of Biscay, over a long time series (15 years PELGAS survey series, see Doray

85 et al. this volume). In addition to species, other biological traits related to fish size and vertical depth distribution were included in the analysis, in an attempt to get more insights on the ecological functions of the identified small pelagic fish communities.

The objectives of the study were to: i) identify and assess the typical species/size composition and spatial distribution of spring small pelagic fish communities in Biscay; ii) characterise the fish communities' spatial

90 and temporal variation over the series and their characteristic scales, iii) relate the fish communities to concurrent hydrological conditions to define habitats, and discuss their ecological function. Small pelagic fish were classified according to the combination of the large (species) and small scale (size, depth distribution) functional traits provided by the acoustic-trawl biomass estimation procedure.

We applied a multivariate, multi-table method, the Multiple Factor Analysis (MFA, Escofier and Pagès, 1994),

95 to ordinate in a unique compromise space standard raster maps cells, grouped by years. Map cells were described by the biological traits of the fish in a first MFA, and, in a second analysis, by hydrological indices describing the fish abiotic environment. Multiscale gradients identified in the fish- and hydrological MFAs derived spaces were related to identify the potential hydrological factors shaping the spring habitats of Biscay small pelagic fish communities. The within-community interactions between small pelagic fish species are 100 discussed, as well as the potential ecological function of the habitats identified.

\section{Material and methods}

\subsection{Small pelagic fish biomass}

Data were collected during the yearly spring acoustic survey series PELGAS (Doray et al., this volume), 20002015, undertaken by IFREMER on board RV "Thalassa" over the French shelf of the Bay of Biscay in May.

105 The survey design consists of parallel line transects, perpendicular to the isobaths and regularly spaced 12 nautical miles (n.m.) apart, from $43.58 \mathrm{~N}$ to $48.88 \mathrm{~N}$ and from the coast (20 m depth) to the $1000 \mathrm{~m}$ isobath (Figure 1). Fish acoustic densities were registered exclusively during daytime while steaming at 10 knots along the transects, at the $38 \mathrm{kHz}$ frequency, using splitbeam echosounders, calibrated during each survey using a standard method (Demer et al., 2015). Pelagic trawl hauls were performed adaptively during daytime, to inform 
110 on the relative species composition and biological parameters (length, weight, age, etc.) of fish echotraces. Hydrological sampling was conducted at night. Vertical profiles were performed on a regular grid of stations (Figure 1) using a conductivity-temperature-depth (CTD, SBE 19plus V2 SeaCAT) probe fitted with a fluorometer and Niskin bottles. At the same stations, WP2 net casts were conducted to collect information on the hydrobiological environment of fish. See Doray et al. (2014) and Doray et al. (this volume) for details on

115 the PELGAS survey protocols.

Due to the mix of pelagic species and variable schooling characteristics of the Bay of Biscay (Massé et al., 1996), small pelagic fish school echotraces could not be allocated to individual species based on acoustic data only. Fish acoustic densities were echo-integrated within 1 nautical mile (n.m.) long Elementary Distance Sampling Units (EDSU) along transects. They were first allocated to coarse taxonomic categories (echotypes)

120 which were generally composed of several small pelagic fish species with similar echotraces. Nearest trawl hauls were then associated to each echotype combination within the EDSU. The combination of the trawl haul data with the acoustic data allowed to split the acoustic density between species, according to the relative species composition in the catch, and to convert acoustic backscatter into fish abundance by species and echotypes, based on fish mean length and the species' acoustic properties (Simmonds and MacLennan, 2005,

125 section 9; Doray et al., 2010). The acoustic biomass procedure provided biomass (in tons), abundance (in thousands of fish) and mean length (in $\mathrm{cm}$ ) per species, echotypes and EDSU, along the survey track.

Size plays an important role in marine ecosystems (Shin et al., 2005), as it is correlated with most life history traits, and acts as a constraint on metabolic rates and energy assimilation (Reiss, 1991). The organisms' preferred depth layers is also a potentially important biological trait, as vertical gradients tend to be several

130 times larger than the horizontal ones (Simard et al., 2003), hence inducing vertical stratification of marine life. To include all the potential functional traits provided by the biomass assessment procedure, information on fish size and vertical distribution were included in the set of variables describing the small pelagic fish assemblages. A specific "surface" echotype comprised of fish detected and fished between the sea surface and $30 \mathrm{~m}$ depth, for EDSUs where the bathymetry is deeper than $50 \mathrm{~m}$. Other "deeper" echotypes were composed 135 of fish caught closer to the seabed or in "coastal" areas (seabed depth $<50 \mathrm{~m}$ ). Fish biomass was summed, and an average of the mean lengths, weighted by biomass, was computed for all "deeper" echograms, to derive biomass and mean length estimates per species, EDSUs in the deeper layer. This dataset was concatenated with the "surface" dataset, to produce a series of biomass and mean length per species, EDSUs, depth layer 
and survey. Fish biomass was summed over $5 \mathrm{~cm}$ length categories, based on fish mean length estimates, to

140 produce the biomass per species, size category, EDSU, depth layer and survey for further analysis.

Following Petitgas et al. (2014), rare occasions of very high fish biomass values per EDSUs and species were truncated because these may mask the regional patterns of variability. Biomass values per species, EDSU, depth layer, size category and survey that were above the $98 \%$ quantile of the distribution of all the values observed over the series were truncated to the $98 \%$ quantile value.

145 In order to focus on the species commonly observed during the PELGAS series, only species appearing in at least $50 \%$ of the 16 surveys considered were retained for further analysis.

\subsection{Hydrological conditions}

Hydrological conditions were derived from CTD casts (Figure 1). Seven hydrological indices were computed at each CTD station (Planque et al., 2006; Huret et al., 2013) to assess the hydrological conditions experienced

150 by small pelagic fish: surface and bottom temperature, surface salinity, a river plume index, the equivalent freshwater height, and 3 water column stratification indices: the potential energy deficit, the mixed layer maximum depth, and the pycnocline depth. Surface parameters were averaged between 2 and $7 \mathrm{~m}$ depth. Bottom values were recorded at $5 \mathrm{~m}$ above the seabed. The deficit of potential energy is the energy required to homogenize the water column. It increases with stratification and was computed from 0 to $100 \mathrm{~m}$ depth for

155 the profiles where bottom depth exceeded $100 \mathrm{~m}$. The equivalent freshwater height measures the height of accumulated freshwater considering a reference seawater salinity (35.5 psu: mean bottom salinity). It is less sensitive to vertical mixing than surface salinity and is thought to better reflect the recent history and local effect of riverine water discharges in the Bay of Biscay.

\subsection{Block averaging}

160 To allow for the comparison of fish biomass and hydrological indices at different spatial locations, the spatiotemporal series of (truncated) fish biomass and hydrological indices were spatially smoothed over the same spatial grid prior to MFA analysis. The grid mesh size selected was $0.25^{\circ}$ in latitude and $0.25^{\circ}$ in longitude, with origin $x_{0}$ at $43^{\circ} \mathrm{N}$ and $6^{\circ} \mathrm{W}$ (Figure 1). This grid was chosen as a compromise between the number of fish and hydrological samples averaged in each block (or cell), and the grid spatial resolution. For each parameter,

165 the mean in block $\left(i, j, x_{0}\right)$ was the average of the data inside the block, positioned at the block centre. To decondition the block means from the grid origin, the point origin $x_{0}$ was randomized in the lowest left corner 
block 200 times (Petitgas et al., 2014). The 200 values computed within each block were averaged to provide the final parameter estimate in the block. This procedure provided a time series of an annual survey, from 2000 - 2015, of raster (or gridded) standard maps of: i) small pelagic fish biomass per species, size category, depth layer, and ii) hydrological indices.

\subsection{Descriptive maps and statistics}

The recurrent spatial patterns of the small pelagic fish biological traits and their variability were first investigated by producing gridded maps of: i) average and coefficient of variation (CV) of the biomass per species, ii) fish mean lengths, all species pooled together, weighted by biomass, iii) the mean lengths

175 distributions per species, weighted by biomass, and iv) average and CV of all fish biomass in surface vs. deeper depth layers.

\subsection{Multiple Factor Analysis}

Multiple Factor Analysis (MFA) is a popular method for studying several groups of variables defined on the same set of individuals (Escofier\&Pagès, 1994; Pagès, 2014). MFA has been widely applied (see review in

180 Abdi et al., 2013), including in marine science (e.g. Petitgas et al., 2006; Huret et al., 2013).

MFA is a multi-table analysis method used here to characterise consistent pattern across factorial groups of a correlation structure between variables describing individuals. MFA proceeds as a two-step Principal Component Analysis (PCA, Hotelling, 1933). First, separate PCAs are applied to matrices $\mathrm{Y}_{g}$, which are arranged with variables as columns and individuals as rows, and are composed of data belonging to each

185 factorial group $g$. Columns of $\mathrm{Y}_{g}$ are then standardised by the first eigenvalue of the PCA on $\mathrm{Y}_{g}$. This step ensures that the matrices of grouped data have similar weights in the next step. Note that the number of variables considered in each group can differ between groups. A PCA is then performed on an overall matrix obtained by appending all the $\mathrm{Y}_{g}$ matrices, column by column. The MFA provides a unique framework from the overall space of all variables, in which all individuals, variables and groups can be represented (Pagès,

190 2014). MFA compromise space is defined by MFA orthogonal components, which are linear combinations of the overall variables in the matrix that maximise the projected inertia of the centers of gravity of the groups in MFA space (Escofier\&Pagès, 1994).

An individual $i$ is represented in the analysis by a cloud of points ("partial individuals") that correspond to their occurrence in groups. The mean position of individual $i$ in MFA space is computed as the position of the 
centre of gravity of its partial individuals across groups (Pagès, 2014). Similarly, the mean position of group $g$ in MFA space is computed as the position of the centre of gravity of the partial individuals within group $g$. As in a PCA, the average correlation structure between variables can be represented in the MFA compromise space. The MFA components are interpreted by studying the correlation between the variables of each group and the components.

200 Specific descriptive statistics, called contributions (Pagès, 2014), can be calculated to evaluate how much an individual, a variable, or a whole group contributes to the inertia extracted by an MFA component. The contribution of an individual $i$ to MFA axis $s$ is derived by dividing the across-group inertia of individual $i$ partial points, by the inertia of all individuals along axis $s$. This provides the (relative) contribution of individual $i$ to the total inertia along axis $s$ (see details in Pagès, 2014 and Abdi et al., 2013). Contributions take values between 0 (no contribution) and 1 (full contribution), and for a given component, the sum of the contributions of all individuals is equal to 1 (Abdi et al., 2013).

The quality of representation of a mean point (individual $i$ or variable $k$ ) on the MFA factorial space axis of rank $s$ can be assessed by dividing the projected inertia of $i$ on $s$ by the total inertia of $i$ on all axes. This indicator (commonly termed 'cos2') can be added over a number of axes, allowing the user to measure the representativeness of a point by, e.g., a plane (Pagès, 2014).

\subsection{MFA implementation}

To assess the spatial and temporal patterns of small pelagic fish communities and their biotope, separate MFAs were applied to fish biomass, and to hydrological indices.

The gridded maps of fish biomass were grouped into 16 (annual) matrices, with map cell as rows (individuals),

215 and species:size category:depth stratum combinations as columns (variables). After removing constant columns, the 569 variables describing the fish communities were $\log 10(\mathrm{X}+1)$-transformed and standardised (centered-scaled), to reduce skewness. The 16 fish matrices were then submitted to MFA, to define multispecies communities and assess their spatial and temporal patterns.

Similarly, the gridded maps of hydrological indices were grouped into 16 annual matrices, with map cells as rows (individuals), and hydrological indices as columns (variables). The 122 variables describing the hydrological conditions were standardised (centre-scaled by columns) and submitted to MFA.

\subsection{MFA interpretation strategy}


The percentage of total variance explained by the MFA components was assessed and a subset of components, representing a substantial amount of the total variance was then selected for further analysis.

225 The positions, contributions, and quality of representation of mean individuals (cell maps) in the planes defined by the selected set of MFA components were then assessed, to identify significant gradients in the MFA ordination plane. Variables that drove specific MFA components were identified by selecting the variables in each annual group that: i) contributed above average to each component, and ii) displayed an absolute correlation coefficient higher or equal to 0.5 with the selected MFA components. In order to assess if the

230 gradients in the MFA ordination plane were associated with spatial patterns, the coordinates of the mean individuals (cells) on each selected MFA axis were represented at their geographical position, to produce maps of mean individual coordinates on selected MFA axes. Map cells whose contribution was higher or equal to the median of the contributions to each selected MFA components were selected to define contrasted areas, corresponding to gradients extrema on the selected MFA axes.

\subsection{Definition of small pelagic fish communities}

Small pelagic fish communities were defined by analysing the species composition in the different areas defined along MFA gradients in the previous step. They were termed "characteristic" fish communities, by analogy with the "characteristic scales" at which a dominant pattern emerges in hierarchy theory (Allen\&Starr, 1982).

\section{$240 \quad 3.9$. Spatio-temporal dynamics of fish communities}

Mean positions and contributions of fish based MFA groups (years) on the selected MFA planes were analysed to identify years with atypical spatial distributions of small pelagic communities at the scale of the Bay of Biscay.

Anomalies of partial individual coordinates (i.e. the cell:year combinations) on each selected MFA axis $s$ were plotted at their geographical position. Anomalies on MFA axis $s$ were computed as the difference between the partial coordinates and their average on axis $s$. The resulting annual maps of anomalies in the coordinates of the partial individuals on selected MFA axes were analysed to further investigate the local spatio-temporal differences in the distribution of small pelagic fish communities over the series.

\subsection{Definition of habitats of small pelagic fish communities}

250 To investigate the relationships between the main gradients identified in the MFA ordination spaces for fish 
and hydrology, map cells coordinates on selected fish MFA components were projected as supplementary variables in the hydrology MFA compromise space. The correlations between fish and hydrology selected MFA components in the hydrology ordination space were analysed to assess which hydrological factors may influence the spatial distribution of the small pelagic fish communities.

255 Distributions of hydrological factors were analysed within areas with characteristic fish communities, to characterise the envelopes of suitable hydrological conditions that potentially shaped distribution of the fish community during spring in the Bay of Biscay.

Statistical computations were performed using the R statistical language version 3.3.1 (R Core Team, 2016), with the EchoR package for fish biomass computations and block averaging (Doray et al., 2016), FactoMineR

260 package (Le et al., 2008) for MFA, and the raster (Hijmans, 2016) and rasterVis (Perpinan Lamigueiro and Hijmans, 2016) packages for mapping.

\section{Results}

\subsection{Small pelagic fish species distribution}

A total of 9 selected species appeared in at least half of the 16 surveys and were considered to contribute to

265 the Biscay small pelagic fish communities during spring (Table 1), belonging to 3 orders: i) perciforms: boarfish (50\% occurrence), Mediterranean horse mackerel (82\% occurrence), Atlantic chub mackerel (100\% occurrence), Atlantic mackerel (100\% occurrence), and horse mackerel (100\% occurrence), ii) gadiforms: blue whiting (94\% occurrence), and iii) clupeiforms: European anchovy (100\% occurrence), European sardine (100\% occurrence), and sprat (100\% occurrence).

270 Maps of mean biomass and coefficient of variation (CV) for each of the small pelagic fish species are presented in Figure $2 \mathrm{a}$ and $2 \mathrm{~b}$, respectively. Species showed different patterns in distributions and inter-annual variability. Anchovy was consistently distributed in core areas characterised by high mean biomass (Figure 2a) and low CVs (Figure $2 \mathrm{~b}$ ) south of $47^{\circ} \mathrm{N}$, close to the Gironde estuary $\left(45^{\circ} \mathrm{N}\right)$. It also occupied secondary areas in coastal areas north of $47^{\circ} \mathrm{N}$, characterised by average to low mean biomass and high CVs, although

275 less consistently. Core areas for sardine, with high mean abundance and low CV, included northern waters (Bretagne coast $\sim 47^{\circ} \mathrm{N}$ ) and southern Biscay (Landes coast $\sim 44^{\circ} \mathrm{N}$ ). Secondary distribution areas were observed along the shelf break, north of $46^{\circ} \mathrm{N}$. Sprat was typically distributed in coastal areas, north of $45^{\circ} \mathrm{N}$. Other species showed less consistent distribution patterns, with markedly higher CVs. The highest blue whiting 
concentrations were observed along the shelf break from south to north, and north of $46^{\circ} 5 \mathrm{~N}$ and west of $3^{\circ} \mathrm{W}$,

280 over the shelf. However, high CV values over the whole survey area suggest that the species distribution varied substantially from year to year. Atlantic mackerel was consistently distributed in a small core area at the north western end of the Bay of Biscay, north of $47^{\circ} \mathrm{N}$ and west of $4.5^{\circ} \mathrm{W}$. It was found in secondary areas along the shelf break. High Atlantic mackerel concentrations were also observed all over the shelf, north of $46^{\circ} \mathrm{N}$, but the high $\mathrm{CV}$ values in this area indicate that it was not consistently occupied. Atlantic chub mackerel was

285 typically observed in the southern part of the Bay, south of $46.5^{\circ} \mathrm{N}$, with the exception of the shelf break area, where its distribution extended to $47^{\circ} \mathrm{N}$. Biomass $\mathrm{CV}$ values were high at latitudes below $45^{\circ} \mathrm{N}$ and very high above this latitude, indicating substantial variations in the species distribution over the series. Like Atlantic mackerel, horse mackerel core distribution area was restricted to the north western end of the Bay of Biscay, north of $47^{\circ} \mathrm{N}$ and west of $5^{\circ} \mathrm{W}$. High horse mackerel concentrations were also observed in secondary areas

290 along the shelf break between $44.5^{\circ} \mathrm{N}$ and $46.5 \mathrm{~N}^{\circ}$, and near the coast, north of $46^{\circ} \mathrm{N}$. However, the high $\mathrm{CV}$ values in all but the core areas indicate that this species' distribution varied from year to year. Mediterranean horse mackerel distribution was highly variable in the Bay of Biscay over the series, impairing the definition of core distribution areas (Figure 2b). High concentration of this species were observed in secondary areas located in the North Western parts of the study area, north of $47^{\circ} \mathrm{N}$ and west of $54 \mathrm{~W}$, and off the Landes coast,

295 north of $44^{\circ} \mathrm{N}$ and south of $45.5^{\circ} \mathrm{N}$. Boarfish was exclusively observed along the shelf break, north of $45^{\circ} \mathrm{N}$, with a very high year-to year variability.

\subsection{Small pelagic fish size distribution}

Maps of the combined species' mean lengths weighted by biomass revealed a clear positive gradient in onshore-offshore distribution (Figure 3); it was lowest in the Gironde estuary area $\left(45.5^{\circ} \mathrm{N}\right)$ and highest along 300 the shelf break.

At a species level, the dominant length mode of the mean length distribution, weighted by biomass, was between 10 to $15 \mathrm{~cm}$ (Figure 4) and was represented by clupeiforms (sardine, anchovy, sprat), as well as small perciforms (horse and chub mackerels and boarfish) and gadiforms (blue whiting). A secondary size mode was present around $20 \mathrm{~cm}$, made up of large sardine and blue whiting and medium-sized mackerels (S. scombrus,

305 S. colias, T. trachurus, T. mediterraneus). A tertiary mode was observed around $37 \mathrm{~cm}$, made of large mackerels (S. scombrus, S. colias, T. trachurus, T. mediterraneus). 


\subsection{Small pelagic fish depth distribution}

Comparison between the combined small pelagic fish biomass (mean and CV) in surface and deeper depth layers (Figure 5) revealed the presence of a clear negative onshore-offshore gradient in the biomass for small

310 pelagic fish occupying the deeper depths and coastal areas. The core distribution areas for these fish were off the Landes coast, south of $45^{\circ} \mathrm{N}$ and in the coastal areas north of the Gironde estuary $\left(\sim 46^{\circ} \mathrm{N}\right)$ to Belle Ile $\left(\sim 47^{\circ} \mathrm{N}\right)$. Secondary distribution areas included the Gironde estuary $\left(\sim 45.5^{\circ} \mathrm{N}\right)$ and Bretagne coastal areas $(\sim$ $\left.47.5^{\circ} \mathrm{N}\right)$

The mean distribution of small pelagic fish occupying surface layers showed less consistent mean distribution

315 patterns: markedly higher CVs limited a meaningful definition of the core distribution area. Secondary areas were located north of $47^{\circ} \mathrm{N}$, and near the shelf-break, between $45^{\circ} \mathrm{N}$ and $46^{\circ} \mathrm{N}$.

\subsection{Ordination of small pelagic fish MFA}

A total of $34 \%$ of the fish biomass maps variance was explained by the first 3 MFA components, denoted MFA1, MFA2 and MFA3. They explained $15.5 \%, 10.4 \%$ and $8.1 \%$ of the total variance, respectively (Figure

320 6). The projections of mean individuals (cell maps) onto the planes defined by MFA1, MFA2 and MFA3 are relatively well spread on both planes, indicating that their ordination on the MFA planes was satisfactory (Figure 6).

\subsection{Definition of the first MFA components of the small pelagic fish}

The fish biomass variables contributing most to the first 3 components of the fish MFA are presented in Figure 3257.

Biomass of anchovy and chub mackerel in deeper layers were consistently positively correlated with MFA1 over the series. The biomass of the mackerel group in deeper layers was less consistently positively correlated with MFA1. Anchovy, and to a lesser extent sardine biomass in surface layer were also correlated with MFA1 (Figure 7a).

330 In deeper layers, sprat biomass was consistently negatively correlated with MFA2 over the series, except in 2000 and 2012. Anchovy and small sardine biomass were also occasionally negatively correlated with MFA2, while Atlantic mackerel and blue whiting biomass were positively correlated with MFA2 more episodically. Fish biomass in surface layer was generally uncorrelated with MFA2 (Figure 7b).

Correlation patterns between fish variables and MFA3 were less clear and less consistent (Figure 7c). In deeper 335 layers, horse- and Atlantic mackerel biomass were frequently positively correlated with MFA3. In surface 
layers, larger sardine biomass was positively correlated with MFA3.

\subsection{Characteristic of small pelagic fish communities}

Spatial and temporal patterns in the species distribution as a function of the MFA axes are visualised as maps of mean individual map cell coordinates and inertia (Figure 8).

340 Spatial structure in the pelagic fish community on the MFA first variance component MFA1 showed a negative mesoscale ( hundreds of km, sensu Haury et al., 1978) gradient from strongly positive values in SouthEastern Biscay corner, to strongly negative values in North-Western Biscay corner (Figure 8). This means that anchovy and chub mackerel distributions in deeper layers were on average restricted to the south-eastern areas, with high positive correlation with MFA1. The inter-annual fish biomass inertia on MFA1 was higher south

345 of $45^{\circ} \mathrm{N}$, in the core area of anchovy and chub mackerel distribution (Figure 8 ). This indicates that the proportions of MFA1 characteristic species (anchovy and chub mackerel) were more variable in southern Biscay than in northern areas.

A positive, coarse to mesoscale ( tens to hundreds of $\mathrm{km}$ ), onshore-offshore gradient was observed in the spatial structure of MFA2, from strongly negative values in the Gironde estuary area to strongly positive values

350 along the shelf break (Figure 8). This indicates that sprats and other small clupeiforms were generally observed in deeper layers in the Gironde area, and near the coast over the series. The inter-annual fish biomass inertia on MFA2 was higher in the Gironde area, and along the shelf break. This indicates that the relative proportions of MFA2 characteristic species (small sprat and clupeiforms) were more variable over the series in onshore and/or offshore areas than in mid-shelf areas.

355 Spatial structure in the pelagic fish community on MFA3 showed a negative, coarse scale ( tens of km) gradient from strongly positive values in the Fer à Cheval area, to strongly negative values in the Gouf de Capbreton and North-Western areas (Figure 8). This indicates that horse and Atlantic mackerels in deeper layers, and large sardine in surface layers, were consistently observed in the Fer à Cheval area along the series. The inter-annual fish biomass inertia on MFA3 was higher around the Fer à Cheval $\left(\sim 45^{\circ} \mathrm{N}\right)$ and Gouf de 360 Capbreton $\left(\sim 44^{\circ} \mathrm{N}\right)$ shelf break areas. This results points out the areas where the relative proportions of MFA3 characteristic species (deep horse and Atlantic mackerels and surface large sardine) were more variable.

Mean coordinates of map cells contributing above average to MFA axes 1 to 3 are presented in Figure 9. Map cells contributing most to the MFA axes definition form spatially coherent patches located at the extrema of 
MFA coordinates gradients: south-east vs. north-west areas for MFA1, Gironde vs. shelf break for MFA2, Fer

365 à Cheval vs. south-east vs and north-west areas for MFA3. We used those map cells dipoles to define "characteristic" areas where typical small pelagic fish communities were consistently observed during the PELGAS surveys series.

The different groups of small pelagic fish communities (Figure 10) showed that anchovy and chub mackerels were almost exclusively associated with the south-eastern MFA1 area (SE) in deeper layers. Small clupeiforms

370 were dominant in the Gironde estuary, characterised by MFA2 (GIRO) in deeper layers (Figure 10). The Fer à Cheval MFA3 characteristic area (FERA) presented unique proportions of medium to large horse and Atlantic mackerels in deeper layers, as well as higher proportions of large sardine in surface layers, compared to other areas associated with MFA3 (Figure 10). Atlantic mackerel proportions were high in most areas. Typical species of each characteristic areas mixed along the MFA spatial gradients outside of the characteristic 375 areas.

\subsection{Spatio-temporal dynamics of fish communities}

Mean positions and contributions of fish MFA groups (years) to each of the 3 MFA axes are presented in Figure 11. Annual maps of partial individuals coordinates anomalies on the first 3 MFA axes in Figure 12.

All years displayed similar positive coordinates on MFA1 (>0.7), with the exception of $2011(0.32)$ (Figure

380 11). This indicates that anchovy and chub mackerel were widely distributed in the vicinity of the MFA1 positive characteristic area (south-east Biscay) over the series, except in 2011, that was an atypical year in terms of MFA1 characteristic patterns. Maps of partial individuals (cell maps:years pairs) coordinates anomalies on MFA1 (Figure 12a) confirm that an inversion of the SE-NW gradient on MFA1 occurred in 2011, with positive anomalies in the NW area, and negative ones in the SE. This indicates that the characteristic anchovy-chub mackerel MFA1 community displayed an atypical northerly distribution in 2011.

The cloud of mean annual points is more evenly spread on MFA2 and MFA3 axes, indicating no sign of atypical years. Most years had relatively similar coordinates, ranging from 0.4 to 0.7 on MFA2. An inversion of the onshore-offshore MFA2 anomalies gradient could be observed between 2006 and 2011 on one hand, and 2012 on the other hand. This reveals that: i) small clupeiforms were concentrated around the MFA2 390 positive characteristic area (Gironde estuary and coastal areas) in most of years, and particularly in 2006 and 2011, ii) they were more widespread over mid-shelf areas in 2012. 
A majority of years displayed positive coordinates ranging from 0.3 to 0.6 on MFA3 in Figure 11. Year 2005 displayed relatively higher coordinate on MFA3 (0.66). Horse and Atlantic mackerel in deeper layers, and large sardine near the sea surface were hence concentrated in the Fer à Cheval area during most years, and particularly in 2005 , which is confirmed by the high positive anomalies observed in this area in Figure $12 \mathrm{c}$ (Dim3.2005 panel).

\subsection{Hydrology MFA ordination}

A total of $64 \%$ of the variance in the hydrological indices map was explained by the first 3 MFA components, denoted MFA1h, MFA2h and MFA3h. MFA1h, MFA2h and MFA3h explained 30.1\%, 22.2\% and 12.0\%, respectively (Figure 13). The projections of mean individuals (cell maps) onto the planes defined by MFA1h, MFA2h and MFA3h are presented in Figure 13. Clouds of points are well spread on both planes, indicating that their ordination on the MFA planes was satisfactory.

\subsection{Definition of hydrology first MFA components}

The variables contributing most to the first 3 components of the hydrology MFA are presented in Figure 14.

Equivalent freshwater height (negatively) and surface salinity (positively) were correlated with MFA1h over the series. Maximum mixed layer depth displayed a less consistent positive correlation with MFA1h (Figure 14). Therefore the first component of the hydrology MFA was representative of the riverine influence on the Bay of Biscay spring hydrology, with negative MFA1h values indicating high freshwater inputs in the system. Bottom temperature was the only variable that was consistently (negatively) correlated with MFA2h over the

410 series (Figure 14), and represented a thermal gradient in near seabed waters, with negative values being observed in warmer areas. Deficit of potential energy was positively correlated with MFA3h in 7 out of 16 survey years (Figure 14). In those occasions, the MFA3h was related to the level of water column stratification. Positive values were indicative of stronger stratification, although this did not imply higher surface temperatures. MFA3h was however less consistently correlated with hydrological indices than higher-order

415 MFA components.

\subsection{Maps of hydrology MFA coordinates}

Spatial and temporal patterns in the hydrological indices distributions as a function of the MFA axes are visualised as maps of mean individual map cell coordinates and inertia (Figure 15). Spatial structure in the physical oceanography on MFA1h showed a coarse to mesoscale, positive onshore-offshore gradient: strongly 
result was in line with the fact that MFA1h represented the effect of freshwater inputs on hydrology, which are maximum in the main river estuaries, and minimum at the shelf break. Inter-annual hydrological indices inertia on MFA1h suggested that the riverine influence was more variable in front of the Gironde estuary and along the Bretagne coast, and more constant near the shelf-break (Figure 15).

425 A positive mesoscale gradient from strongly negative values near the Landes coast $\left(44^{\circ} \mathrm{N}\right)$ in South-Eastern Biscay, to strongly positive values in the North-West $\left(47.5^{\circ} \mathrm{N}\right.$, Figure 15$)$ was observed in the spatial structure of MFA2h. MFA2h was negatively correlated with bottom temperature, which indicates that the bottom temperature consistently decreased from south-east to north-west Biscay. The inter-annual hydrological indices inertia on MFA2h suggests that bottom temperature was more variable near the extremities of the 430 gradient (Landes coast and north-west Biscay, Figure 15).

Spatial structure in the physical oceanography on MFA3h showed a coarse-scale, negative, radial gradient, from positive values in the centre of the Bay of Biscay, to negative values along the coast, and null values at the shelf break (Figure 15). MFA3h was positively correlated with the deficit of potential energy, which indicates that the water column stratification was higher in the centre and mid-shelf area of the Bay of Biscay,

435 average at the shelf break, and weaker near the coastal areas of the survey series. MFA3h and stratification tended to be very variable in a small area in central Biscay and variable near the shelf break and the coast (Figure 15).

\subsection{The spring habitats of small pelagic fish communities in the Bay of Biscay}

MFA of fish biomass and hydrological indices maps allowed for the characterisation of several gradients in

440 the factorial space, that corresponded to spatial gradients from coarse to mesoscale in geographical space. Small pelagic fish biomass and their hydrological spring environment therefore appeared to be both spatially structured at several scales over the PELGAS series.

To assess the potential overlaps between the multiscale spatial gradients in the distribution of fish communities and of hydrological conditions, the first 3 components of the fish MFA were projected as supplementary

445 variables in the hydrology MFA space (Figure 16).

The first variance component of the fish MFA (MFA1) was negatively correlated with the second variance component of the hydrology MFA (MFA2h) (correlation coefficient $=-0.73$ ). The correlation between fish MFA1 and hydrology MFA2h in factorial space translated into geographical space, where both gradients 
displayed similar south-east / north-west mesoscale orientations. MFA1-associated small pelagic fish 450 communities were indeed distributed along a bottom temperature gradient: anchovy and chub mackerel in deeper layers were consistently found in south-eastern areas where bottom temperatures were higher. Characteristic habitats of MFA1-associated small pelagic fish communities were defined based on the distribution of bottom temperature, the characteristic hydrological indicator defining MFA2h, in MFA1 characteristic areas (Table 2). Mean bottom temperature was significantly higher (Student's t-test pvalue $<2.2 \mathrm{e}-$

455 16) in MFA1 south-east than in MFA1 north-west characteristic areas (Table 2). Bottom temperature minima were similar in both areas, whereas bottom temperature maximum was $2^{\circ} \mathrm{C}$ higher in the south-east area (Table 2). MFA1-associated small pelagic fish community characterised by the presence of anchovy and chub mackerel in deeper layers appeared to cope better with, and/or sought higher mean to maximum temperature than northern fish assemblages.

460 The second variance component of the fish MFA (MFA2) was significantly positively correlated with the first variance component of the hydrology MFA $($ MFA1h) $($ correlation coefficient $=0.82)$. Map cell coordinates on MFA2 and MFA1h displayed similar coarse to mesoscale onshore-offshore spatial gradients. MFA2-type small pelagic fish communities were distributed along a riverine influence gradient, with small clupeiforms in deeper layers being consistently found in coastal areas, where the riverine freshwater inputs were higher.

465 Characteristic habitats of MFA2-associated small pelagic fish communities were defined based on the distribution in MFA2 characteristic areas of the typical hydrological indicators defining MFA1h (surface salinity in Table 2). Mean surface salinity was significantly lower in the Gironde than in offshore MFA2 characteristic areas (Table 2). Maximum surface salinity values were similar in both areas, whereas minimum surface salinity values were 2 PSU lower in the Gironde area (Table 2). MFA2 coastal small pelagic fish 470 community appeared to better cope, and/or seek, lower average to minimum surface salinities compared to offshore fish assemblages.

The third variance component of the fish MFA (MFA3) was not correlated with any of the hydrology MFA components. This indicates that the spatial distribution of the MFA3 associated community was not likely to be shaped by the variable hydrological conditions that occurred in the Fer à Cheval area. 


\section{Discussion}

\subsection{Application of MFA to multivariate maps series}

The multi-table, MFA-based methodology proposed in this paper allowed for the spatio-temporal analysis of series of maps describing e.g. species communities and multiple environmental conditions.

Similar to Empirical Orthogonal Function analysis (EOF, Preisendorfer, 1988; Petitgas et al., 2014), individuals were represented by map cells. Contrary to EOF however, map cells were not described by successive measurements of a single variable, but by an unrestricted number of variables (in this study fish biomass per biological trait, and hydrological indices). A temporal component was introduced in the analysis by grouping the data according to their sampling time. MFA specific weighting ensured that all groups had the same weight in the analysis, hence allowing to analyse groups with different number of variables (to account

485 for instances where a species was not observed over all the series). The possibility offered by MFA to ordinate individuals described by an unrestricted number of variables, potentially of different type (numeric or factorial), makes it a suitable tool to analyse complex spatial ecological datasets collected at fixed locations over time. MFA is also easy to implement and computationally un-intensive, relatively to the potentially very large amount of variability in the original dataset.

490 In this paper, the amount of variance explained by the first 3 MFA components varied, depending on the total variability of the dataset and its variance structure. The amount of variance explained by the first 3 MFA components varied from $34 \%$ in the case of large and heterogeneous fish dataset (569 columns), to $64 \%$ in the case of the smaller and more homogeneous hydrology dataset (122 columns). A substantial amount of the variance in the fish dataset remained unexplained by the higher order MFA analysis components. When dealing

495 with complex datasets, consisting of considerable spatial, temporal and biological variability, the analyst should aim to extract the relevant details at the scales of interest, rather than trying to explain all the smallscale variability, that can be considered as noise at larger scales (Levin, 1992). MFA is well suited to achieve such multi-scale analysis, as it provides orthogonal hierarchized components of the variability in the original dataset, which enables the user to characterise spatio-temporal patterns from large scale (higher order MFA

500 components) to fine scale (lower order MFA components). In this interannual, coarse to mesoscale study, MFA proved to be a valuable method to capture the larger scale spatial patterns in the fish and hydrology datasets that were used to define spring habitats of Biscay small pelagic fish communities. 
Spatial autocorrelation between map cells was not explicitly modelled in this paper. Instead, the spatial structures in the original maps of biological traits within fish (Figures 2, 3,5 ) were combined and summarised in higher order MFA components (Figure 8), without imposing contiguity constraints. This offers more flexibility, and does not require assumptions about the spatial structure of the data, hence allowing handling of e.g. non stationary distributions (Georgescu et al., 2009).

Contrary to other multitable analysis, such as STATIS (Lavit et al., 1994), a practical advantage of MFA is to allow for the representation of individuals, variables and groups in a single framework (Pagès, 2014). In this

510 paper, the MFA common framework was used to describe the ordination plane of the individuals with reference to original variables in the fish MFA, and to use this information to interpret the group (years) positions in the MFA compromise space. Grouping the data by sampling years also allowed to identify atypical years during which fish communities distributions had departed from the average patterns, at the regional (Figure 11) and local scales (Figure 12).

515 Vaz et al. (2007) have studied the temporal variability in a demersal fish assemblage by applying a PCA on a 16 years series of bottom trawl data and projecting the years as a supplementary variable. This approach would provide similar results to those obtained with a MFA, if the first eigenvalues of each annual group are similar (Pagès, 2014). If the groups have very different variance structures (which may happen if they are e.g. composed of different numbers of variables), MFA is preferred, as its specific weighting ensures that all groups

520 will be treated equally in the analysis.

The ordination plane of the fish MFA appeared to be rather insensitive to the survey years included in the analysis. Applying the same methodology to the 2006-2015 surveys subset instead of 2000-2015 did not substantially change the variables contributing most to the first 3 fish MFA components nor to the spatial patterns of fish MFA1 and MFA2. Changes in the spatial patterns of MFA3 occurred however with the 2006-

5252015 dataset. This indicates that the first order variance components of the fish maps (represented by MFA12) might have been similar over the series, whereas shorter time scale variations were reflected in higher order MFA components (> 3).

Data collected during a new survey could be incorporated in two ways in our MFA model, to test for the ordination robustness: i) as a new group of data in the fish and hydrology MFAs, to test if their inclusion 530 modifies the MFA ordination planes, ii) as supplementary variables, to assess the new dataset resemblance 
with previous surveys.

\subsection{Definition of fish communities}

MFA, like other multivariate ordination methods brings out general gradients. Ordination is often used to supplement clustering methods when the variance structure of the objects under study is not continuous 535 (Legendre\&Legendre, 2012). Ordination methods are classically combined with clustering procedures to identify contrasting groups of individuals within ordination gradients (Legendre and Legendre, 2012). For example, Petitgas et al. (2006) combined MFA and hierarchical ascendant clustering on hydrobiological stations data to classify locations of sampling stations. As the spatial gradients of map cell coordinates on high order fish MFA axes were highly continuous in our study (Figure 8a), the definition of an optimal number of 540 map cell clusters within the fish MFA gradients could not be objectively justified. Moreover, in MFA, the projection of an individual (map cell) in the compromised space is the centre of gravity of its (here annual) partial individuals. It was then essential to assess the contribution of the individual to the MFA axis of interest (i.e. the dispersion of its partial points), together with its coordinates, to properly interpret its position in the MFA space (Pagès, 2014). We therefore did not use a clustering method in conjunction with MFA ordination

545 to identify areas with homogeneous fish assemblage. Instead, we selected the map cells with the highest contribution to each higher-order MFA axes. Those map cells contributing above average to the first 3 fish MFAs components formed spatially coherent characteristic areas located at MFA axes extrema. These were able to define areas where the small pelagic fish assemblage consistently showed contrasting species compositions over time.

550 Fish species assemblages were defined with reference to the biological traits that were consistently correlated with the first 3 MFA components. The "species" category was the biological trait that was the most frequently correlated with the fish MFA first components. "Size" was generally not able to describe MFA components, probably as species was a good proxy for size in the Biscay small pelagic fish community (Figure 4). Vertical distribution of fish characterised the MFA3 component within the fish community (surface sardine and deeper mackerels). Vertical distribution might provide interesting supplementary information on the function of fish communities and habitats, as fish living close to the surface and near the sea bed usually experience different biotic and abiotic conditions.

Previous studies (Vaz et al.,2007) analysed time series of communities of demersal fish using the TWINSPAN method (Two-Way INdicator SPecies Analysis, Hill, 1979), coupled with PCA and indicator kriging (Isaaks 
and Shrivastava, 1989). The same objectives were achieved in this study using MFA, which is probably more suitable for more mobile small pelagic fish.

\subsection{Spatial smoothing of data on a common grid before MFA}

The grid size chosen here $\left(0.25^{\circ}\right.$ latitude $\mathrm{x} 0.25^{\circ}$ longitude) was the smallest still able to produce gridded maps of fish biomass and hydrological indices with enough sample points in each grid cell. It was compatible with

565 the known distribution patterns of small pelagic fish (Petitgas, 2003) and hydrological indices (Woillez et al., 2010) in the area. The common grid resolution resolved coarse to mesoscale spatial patterns in both fish and hydrology MFA coordinates distribution.

\subsection{Habitat definition}

Various studies have predicted community distributions of marine organism as a function of environmental conditions (e.g. Petitgas et al. ,2006; Certain et al.,2011; Thioulouse et al., 2004; Vaz et al., 2007; Whaley et al., 2007; Bonnano et al. , 2015). In our case, the dataset describing fish communities was quite complex, as it included three different biological traits (species, size and depth distribution), was collected over a 15 years series, and during a season, spring, where environmental conditions, and resulting patterns in fish distributions, are known to be highly variable (Huret et al., 2013; Huret, this volume). Due to the large amount of variability

575 in the fish dataset, the cell-wise statistical modelling of fish community biomass as a function of hydrological conditions maps by Redundancy Analysis (Wollenberg, 1977) explained less than 3\% of the fish dataset variance. We then focused on the study of correlations between fish and hydrology gradients, rather than on drawing firm statistical inference between fish and hydrology datasets at the map cell scale. Significant correlations between distributions gradients of fish and hydrology have been revealed by projecting the map

580 cell coordinates on the first 3 fish MFA components in the hydrology MFA plane. Characteristic habitats have been defined on the basis of the hydrological conditions encountered by small pelagic fish communities occupying MFA gradients extrema. In contrast to classical statistical regression techniques, the approach presented here cannot predict fish community habitats, but provides information on the average environmental conditions encountered by contrasted fish communities over the series.

This study confirmed previous knowledge on the spring distribution of the main small pelagic fish species in the Bay of Biscay (ICES, 2010; Certain et al., 2011, Petitgas et al. 2014). New insights on the spring distribution of less abundant and frequent species (S. colias, T. mediterraneus, C. aper, M. poutassou) were 
provided for the first time (Figure 2). The existence of an area-wide negative offshore-onshore gradient in size

590 in the Biscay small pelagic fish spring community, previously observed (Certain et al., 2011; Petitgas et al., 2011), was also confirmed (Figure 3). Evidence for spatial trends in the distribution of surface vs. deeper small pelagic fish schools was provided for the first time in the Bay of Biscay in springtime (Figure 5).

\subsection{Spatial patterns of Biscay hydrology in springtime}

The presence of a negative bottom temperature gradient from south-east to north-west Biscay in spring evidenced by this study contradicts previous modelling results (Planque et al., 2006), which indicated that the average bottom temperature was higher in spring in northern Biscay over the 1987-2001 period.

Unlike satellite measurements, which displayed a $2-3^{\circ} \mathrm{C}$ negative latitudinal gradient from south to north during spring in Biscay, (Huret et al., this volume) in situ surface temperature maps for the same period did not show clear gradients. Surface temperature was weakly correlated with the first hydrology MFA 600 components. The absence of a gradient in surface temperature was likely due to the fact that surface waters warmed while the ship was moving northwards during the 6 week survey.

\subsection{Biscay small pelagic fish community spring habitats}

Chub mackerel is recorded in the Bay of Biscay from summer to early winter (Castro Hernández and Santana Ortega, 2000) and favours temperatures ranging from $10-12^{\circ} \mathrm{C}$ to $23-27^{\circ} \mathrm{C}$ (Schaefer, 1986). Adult anchovies

605 migrate to south-eastern Biscay in winter to feed in advance of spawning (ICES, 2010, Politikos et al., 2015). Petitgas et al. (2014) showed that bottom temperature was one of the factors controlling the mesoscale variability in Biscay anchovy spatial distribution over time. The spatial segregation of anchovy and chub mackerel in south-eastern Biscay in spring evidenced by this study was likely due to their seasonal migration patterns, probably related to temperature preferences. Anchovy moreover utilises South-Eastern Biscay areas

610 as spawning grounds in springtime (Planque et al., 2007).

The small clupeiforms coastal habitat identified in this study corresponds to recurrent anchovy and sardine spring spawning sites (Planque at al., 2007). No information on sprat spawning in the Bay of Biscay was available. The presence of small spawning anchovy and sardine in the low salinity waters was probably related to the high productivity of these coastal areas that are likely good feeding grounds for clupeiforms.

615 S. scombrus, S. pilchardus, T. trachurus and M. poutassou were present in all characteristic communities, but were not restricted to specific habitats (Figure 10). Those species indeed display a large spatial extension in 
north-east Atlantic waters, where adults achieve large scale migrations encompassing various hydrological conditions (ICES, 2010). They have been found in most areas of the Bay of Biscay over the series (Figure 2b), with large year to year variations in their distribution (Figure 2c). This result suggests that the distributions of those cosmopolitan species might be less influenced by the Bay of Biscay local hydrological conditions, and more likely shaped by larger scale process, with characteristic scales commensurate to the vast spatial extension of their populations. Clupeiform species with spatial distributions restricted to the Bay of Biscay and neighbouring areas (anchovy, sprat, small sardine) conversely appeared to be more influenced by local hydrological conditions in the Bay.

625 Smaller north-east Atlantic sardine (<18 cm length) are thought to first live within local, coastal populations and to recruit to mixed, offshore population components after reaching $18 \mathrm{~cm}$ length (ICES, 2010). The bigger sardine $(>20 \mathrm{~cm})$ occupying the surface layers of the characteristic offshore habitats identified in this study could be part of the mixed offshore population component. Our results suggest that the mixed offshore sardine population component might be distributed closer to the sea surface than local coastal population, at least in

630 springtime in the Bay of Biscay.

Fish MFA3 gradient was not correlated with any of the hydrological indices considered here. This may indicate that the spring distribution of MFA3 characteristic species was shaped by environmental factors that were not included in the analysis (e.g. planktonic prey abundance, or mesoscale activity), or that the concentration of fish communities in those characteristic areas was driven by intrinsic population behaviour, such as e.g.

635 spawning migration. S. scombrus, T. trachurus are in fact known to undergo a spawning migration to northern areas at the time of the PELGAS surveys, whereas M. poutassou is thought to be migrating back to feeding areas after spawning (ICES, 2010). The spatial distributions of these migrating species, and potentially of large S. pilchardus, whose migrations are poorly known, are likely not stationary and may still be in progress during the survey. The spatial and temporal extent of these migrations is large, relatively to the sampling scales and

640 it is therefore not likely that the biomass estimates are adversely affected. It is more likely to introduce extra variability at small spatial scales.

\subsection{Biotic interactions within small pelagic fish communities}

Small pelagic adult fish belonging to the characteristic communities described in this paper preyed on similar phytoplanktonic and mesozooplanktonic organisms (ICES, 2010; Bachiller and Irigoien, 2015), and therefore belonged to the same trophic guild (sensu Fauth et al, 1996). Intra-guild competition for food, egg predation 
and egg cannibalism are potentially the main biotic interactions that occurred in these fish communities, during periods when planktonic prey were scarce (Bachiller \& Irigoien, 2015). Bachiller et al. (2015) concluded that egg predation by sardine, sprat and Atlantic and Atlantic Chub mackerel, as well as egg cannibalism, could have a significant negative effect on anchovy egg mortality in the Bay of Biscay. However, in absence of data

650 on planktonic prey availability relatively to small pelagic fish trophic needs, one cannot assess the magnitude of competition for food and egg predation and cannibalism within Biscay small pelagic fish communities.

\section{Conclusions}

This study represents the first attempt to analyse the Biscay small pelagic fish at the community scale, map the spatial and temporal dynamics of the communities, and assess their characteristic habitats. The unique dataset

655 collected during the PELGAS survey series, provided a multiscale overview of the horizontal and vertical distribution of small pelagic fish species and size-classes, as well as hydrological conditions in the Bay of Biscay in springtime from 2000 to 2015 . The distributions of widely spread and highly migratory species ( $S$. scomber, S. colias, T. trachurus, M. poutassou, S. pilchardus) and of species forming local populations in the Bay of Biscay (E. encrasicolus, S. sprattus, small S. pilchardus) observed in spring were jointly analysed to

660 define characteristic fish communities.

Fish assemblages were most variable along a latitudinal gradient, whereas hydrology variability was highest along an inshore to offshore gradient. Characteristic fish habitats were identified along those gradients. They appeared to be directly shaped at mesoscale by hydrological parameters physiologically important for adult fish (bottom temperature), and indirectly at coarse to mesoscale by hydrological parameters identifying

665 favourable areas for feeding or fish eggs and larvae development. Most small pelagic fish communities indeed utilised the Biscay characteristic habitats identified in this study as spawning grounds in springtime.

The inclusion of other potentially influential environmental proxies, such as small pelagic fish phyto and mesozooplanktonic prey, and mesocale hydrological activity (eddies, fronts...), in the MFA of environmental conditions would be a way to further assess the hydrobiological factors combinations that shape the distribution

670 of small pelagic fish from coarse to mesoscale. MFA provided a suitable framework to analyse the interactive combinations of environmental proxies occurring at different scales, as it can accommodate both categorical (e.g. presence-absence of a smaller scale ocean process, eddy of front) and continuous (e.g. intensity of a larger 
scale ocean process, such as upwelling) variables.

Most of the small pelagic species of Biscay spring communities are commercially exploited by fishing (i.e. $E$.

encrasicolus, S. pilchardus, S. scombrus, M. poutassou, T. trachurus; ICES, 2010), and are important forage species for higher trophic levels, especially cetaceans (Lassalle et al., 2011; Spitz et al., 2011). Maps of characteristic small pelagic fish habitats in spring identified in this study could contribute to the quantitative identification of key sites for preserving biodiversity, and/or productive fish stocks. The area off the Gironde estuary in spring has e.g. been identified as an essential habitat for anchovy (Vaz and Petitgas, 2002) that

680 should be protected (Villamor et al., 2007). Our study confirmed that this area is a key habitat not only for anchovy, but for all small clupeiform species. The spatially-explicit results at the community level derived from this study might hence contribute to inform spatially based ecosystem management policies aiming at achieving maximum sustainable fishing yields, and/or good ecological status objectives. The definition of Biscay small pelagic characteristic spring habitats may be updated every year by including new data from the

685 PELGAS survey, and their temporal variations assessed, to provide scientific support for evaluating and eventually adjusting spatial management policies.

\section{Acknowledgements}

This study was supported by Ifremer. PELGAS has been funded by the European Common Fishery Policy Data Collection Framework, the Marine Strategy Framework Directive, and Ifremer. We want 690 to acknowledge the joint efforts of R/V Thalassa crews and PELGAS scientists that made the survey possible. We thank Paul Bourriau for taking care of the CTD casts and the equipment and Patrick Grellier and Erwan Duhamel for managing the fish biological data collection. We are indebted to Dr. Jeroen Van Der Kooij for editing the English text. 


\section{References}

Abdi, H., Williams, L.J., Valentin, D., 2013. Multiple factor analysis: principal component analysis for multitable and multiblock data sets. WIREs Comput Stat. doi:10.1002/wics.1246

Allen, T., Starr, T., 1982. Hierarchy perpectives for ecological complexity. Univ. Of Chicago, Chicago, USA.

Bachiller, E., Cotano, U., Ibaibarriaga, L., Santos, M., Irigoien, X., 2015. Intraguild predation between small pelagic fish in the Bay of Biscay: impact on anchovy (Engraulis encrasicolus L.) egg mortality. Mar. Biol. 162, 1351-1369. doi:10.1007/s00227-015-2674-0

Bachiller, E., Irigoien, X., 2015. Trophodynamics and diet overlap of small pelagic fish species in the Bay of Biscay. Mar. Ecol. Prog. Ser. 534, 179-198. doi:10.3354/meps11375

Bertrand, A., Habasque, J., Hattab, T., Hintzen, N.T., Oliveros-Ramos, R., Gutiérrez, M., Demarcq, H., Gerlotto, F., 2016. 3-D habitat suitability of jack mackerel Trachurus murphyi in the Southeastern Pacific, a comprehensive study. Prog. Oceanogr. 146, 199-211. doi:10.1016/j.pocean.2016.07.002

Bertrand, A., Segura, M., Gutierrez, M., Vasquez, L., 2004. From small-scale habitat loopholes to decadal cycles: a habitat-based hypothesis explaining fluctuation in pelagic fish populations off Peru. Fish Fish. 5, 296-316.

Bonanno, A., Giannoulaki, M., Barra, M., Basilone, G., Machias, A., Genovese, S., Goncharov, S., Popov, S., Rumolo, P., Di Bitetto, M., Aronica, S., Patti, B., Fontana, I., Giacalone, G., Ferreri, R., Buscaino, G., Somarakis, S., Pyrounaki, M.-M., Tsoukali, S., Mazzola, S., 2014. Habitat Selection Response of Small Pelagic Fish in Different Environments. Two Examples from the Oligotrophic Mediterranean Sea. PLoS ONE 9, e101498. doi:10.1371/journal.pone.0101498

Bonanno, A., Zgozi, S., Basilone, G., Hamza, M., Barra, M., Genovese, S., Rumolo, P., Nfate, A., Elsger, M., Goncharov, S., Popov, S., Mifsud, R., Bahri, T., Giacalone, G., Fontana, I., Buongiorno Nardelli, B., Aronica, S., Ceriola, L., Patti, B., Ferreri, R., Colella, S., Volpe, 
G., Mazzola, S., 2015. Acoustically detected pelagic fish community in relation to environmental conditions observed in the Central Mediterranean sea: a comparison of Libyan and Sicilian-Maltese coastal areas. Hydrobiologia 755, 209-224. doi:10.1007/s10750-015-2234-0

Borcard, D., Legendre, P., Drapeau, P., 1992. Partialling out the spatial component of ecological variation. Ecology 73, 1045-1055.

Castro Hernández, J.J., Santana Ortega, A.T., 2000. Synopsis of biological data on the chub mackerel (Scomber japonicus Houttuyn, 1782). FAO Fish Synop 77.

Certain, G., Massé, J., Van Canneyt, O., Petitgas, P., Doremus, G., Santos, M.B., Ridoux, V., 2011. Investigating the coupling between small pelagic fish and marine top predators using data collected from ecosystem-based surveys. Mar. Ecol. Prog. Ser. 422, 23-39.

Cury, P., Bakun, A., Crawford, R., Jarre, A., Quinones, R., Shannon, L., Verheye, H., 2000. Small pelagics in upwelling systems: patterns of interaction and structural changes in "wasp-waist" ecosystems. ICES J Mar Sci 57, 603-618.

Demer, D.A., Berger, L., Bernasconi, L., Bethke, E., Boswell, K.M., Chu, D., Domokos, R., Dunford, A.J., Faessler, S.M.M., Gauthier, S., Hufnagle Jr, L.C., Jech, J.M., Le Bouffant, N., Lebourges-Dhaussy, A., Lurton, X., Macaulay, G.J., Perrot, Y., Ryan, T.E., ParkerStetter, S., Stienessen, S., Weber, T., Williamson, N., 2015. Calibration of acoustic instruments. ICES Coop. Res. Rep. 133.

Doray, M., Badts, V., Massé, J., Duhamel, E., Huret, M., Doremus, G., Petitgas, P., 2014. Manual of fisheries survey protocols. PELGAS surveys (PELagiques GAScogne). Manuel des protocoles de campagne halieutique Ifremer No. 30259. http://doi.org/10.13155/30259

Doray, M., Massé, J., Petitgas, P., 2010. Pelagic fish stock assessment by acoustic methods at Ifremer. Rapp Int Ifremer DOP/DCN/EMH 10-02, 1-17.

Doray, M., Petitgas, P., Saraux, C., Cornou, A.S., 2016. EchoR: R package for computing indices of the state of fish population and communities, based on fisheries acoustic data, $\mathrm{R}$ package. 


\section{https://forge.ifremer.fr/plugins/mediawiki/wiki/echor/index.php/Accueil}

Doray, M., Petitgas, P., Romagnan, J.B., Huret, M., Duhamel, E., Dupuy, C., Spitz, J., Authier, M., Sanchez, F., Berger, L., Dorémus, G., Bourriau, P., Grellier, P., Massé, J., this volume. The PELGAS survey: ship-based integrated monitoring of the Bay of Biscay pelagic ecosystem. Prog. Oceanogr.

Escofier, B., Pagès, J., 1994. Multiple factor analysis (AFMULT package). Comput. Stat. Data Anal. 18, 121-140. doi:10.1016/0167-9473(94)90135-X

Fauth, J.E., Bernardo, J., Camara, M., Resetarits, W.J., Van Buskirk, J., McCollum, S.A., 1996. Simplifying the Jargon of Community Ecology: A Conceptual Approach. Am. Nat. 147, 282-286. doi:10.1086/285850

Fréon, P., Cury, P., Shannon, L., Roy, C., 2005. Sustainable exploitation of small pelagic fish stocks challenged by environmental and ecosystem changes: a review. Bull Mar Sci 76, $385-462$.

Garcia, S.M., Zerbi, A., Aliaume, C., Do Chi, T., Lasserre, G., 2003. The ecosystem approach to fisheries. FAO Fisheries Technical Paper No. 443. FAO, Rome.

Gastauer, S., Fässler, S.M.M., O’Donnell, C., Høines, Å., Jakobsen, J.A., Krysov, A.I., Smith, L., Tangen, Ø., Anthonypillai, V., Mortensen, E., Armstrong, E., Schaber, M., Scoulding, B., 2016. The distribution of blue whiting west of the British Isles and Ireland. Fish. Res. 183, 32-43. doi:10.1016/j.fishres.2016.05.012

Georgescu, V., Soubeyrand, S., Kretzschmar, A., Laine, A.-L., 2009. Exploring Spatial and Multitype Assemblages of Species Abundances. Biom. J. 51, 979-995. doi:10.1002/bimj.200900055

Gomes, M., 2001. Spatial patterns of groundfish assemblages on the continental shelf of Portugal. ICES J. Mar. Sci. 58, 633-647. doi:10.1006/jmsc.2001.1052

Guisan, A., Zimmermann, N.E., 2000. Predictive habitat distribution models in ecology. Ecol. Model. 135, 147-186. doi:10.1016/S0304-3800(00)00354-9 
Haury, L.R., McGowan, J.A., Wiebe, P.H., 1978. Patterns and processes in the time-space of plankton distributions, in: Steele, J.H. (Ed.). Plenum Press, Erice (Italy), pp. 277-327.

Hijmans, R.J., 2016. raster: Geographic Data Analysis and Modeling, R package.

Hill, M.O., 1979. TWINSPAN: a FORTRAN program for arranging multivariate data in an ordered two-way table by classification of the individuals and attributes, New York: Cornell University Ithaca. Ed., Section of Ecology and Systematics.

Hotelling, H., 1933. Analysis of a complex of statistical variables into principal components. J. Educ. Psychol. 24, 417-441. doi:10.1037/h0071325

Huret, M., Sourisseau, M., Petitgas, P., Struski, C., Léger, F., Lazure, P., 2013. A multi-decadal hindcast of a physical-biogeochemical model and derived oceanographic indices in the Bay of Biscay. J. Mar. Syst. 109-110, S77-S94. doi:10.1016/j.jmarsys.2012.02.009

Huret, M., Bourriau, P., Doray, M., Gohin, F. and Petitgas, P. This volume. Survey timing vs. ecosystem scheduling: degree-days to underpin observed interannual variability in marine ecosystems. Prog. Oceanogr.

ICES, 2010. Life cycle spatial patterns of small pelagic fish in the Northeast Atlantic. ICES Coop. Res. Rep. 93.

Isaaks, E., Shrivastava, R., 1989. An introduction to applied geostatistics. Oxford University Press, Oxford.

Lassalle, G., Lobry, J., Le Loc’h, F., Bustamante, P., Certain, G., Delmas, D., Dupuy, C., Hily, C., Labry, C., Le Pape, O., Marquis, E., Petitgas, P., Pusineri, C., Ridoux, V., Spitz, J., Niquil, N., 2011. Lower trophic levels and detrital biomass control the Bay of Biscay continental shelf food web: Implications for ecosystem management. Prog. Oceanogr. 91, 561-575. doi:10.1016/j.pocean.2011.09.002

Lavit, C., Escofier, B., Sabatier, R., Traissac, P., 1994. The ACT (statis method). Comput. Stat. Data Anal. 18, 97-119.

Le Pape, O., Delavenne, J., Vaz, S., 2014. Quantitative mapping of fish habitat: A useful tool to 
design spatialised management measures and marine protected area with fishery objectives. Ocean Coast. Manag. 87, 8-19. doi:10.1016/j.ocecoaman.2013.10.018

Le, S., Josse, J., Husson, F., 2008. FactoMineR: An R Package for Multivariate Analysis. J. Stat. Softw. 25, 1-18. doi:10.18637/jss.v025.i01

Legendre, P., 1993. Spatial Autocorrelation: Trouble or New Paradigm? Ecology 74, 1659-1673. doi:10.2307/1939924

Legendre, P., Galzin, R., Harmelin-Vivien, M.L., 1997. Relating Behavior to Habitat: Solutions to the Fourth-corner Problem. Ecology 78, 547. doi:10.2307/2266029

Legendre, P., Legendre, L., 2012. Numerical Ecology. Elsevier, Amsterdam.

Levin, S., 1992. The problem of pattern and scale in ecology. Ecology 73, 1943-1967.

Levin, S.A., 2000. Multiple Scales and the Maintenance of Biodiversity. Ecosystems 3, 498-506. doi:10.1007/s 100210000044

Levin, S.P., Fogarty, M.J., Murawski, S.A., Fluharty, D., 2009. Integrated Ecosystem Assessments: Developing the Scientific Basis for Ecosystem-Based anagement of the Ocean. PLOS Biol. 7, 1-6.

Massé, J., Koutsikopoulos, C., Patty, W., 1996. The structure and spatial distribution of pelagic fish schools in multispecies clusters: an acoustic study. ICES J Mar Sci 53, 155-160.

Mueter, F., Norcross, B., 1999. Linking community structure of small demersal fishes around Kodiak Island, Alaska, to environmental variables. Mar. Ecol. Prog. Ser. 190, 37-51. doi:10.3354/meps 190037

Pagès, J., 2014. Multiple Factor Analysis by Example Using R, Chapman and Hall/CRC.

Perpinan Lamigueiro, O., Hijmans, R.J., 2016. rasterVis, R package version. meteoForecast.

Petitgas, P., 2003. A method for the identification and characterization of clusters of schools along the transect lines of fisheries-acoustic surveys. ICES J Mar Sci 60, 872-884.

Petitgas, P., Doray, M., Massé, J., Grellier, P., 2011. Spatially explicit estimation of fish length histograms, with application to anchovy habitats in the Bay of Biscay. ICES J. Mar. Sci. J. 
Cons. https://doi.org/10.1093/icesjms/fsr139.

Petitgas, P., Doray, M., Huret, M., Massé, J., Woillez, M., 2014. Modelling the variability in fish spatial distributions over time with empirical orthogonal functions: anchovy in the Bay of Biscay. ICES J. Mar. Sci. 71, 2379-2389. doi:10.1093/icesjms/fsu111

Petitgas, P., Massé, J., Bourriau, P., Beillois, P., Delmas, D., Herbland, A., Koueta, N., Froidefond, J., Santos, M., 2006. Hydro-plankton characteristics and their relationship with sardine and anchovy distributions on the French shelf of the Bay of Biscay. Sci Mar 70S1, 161-172.

Planque, B., Bellier, E., Lazure, P., 2007. Modelling potential spawning habitat of sardine (Sardina pilchardus) and anchovy (Engraulis encrasicolus) in the Bay of Biscay. Fish Ocean. 16, 1630.

Planque, B., Lazure, P., Jegou, A., 2006. Typology of hydrological structures modelled and observed over the Bay of Biscay shelf. Sci. Mar. 70S1, 43-50.

Politikos, D.V., Huret, M., Petitgas, P., 2015. A coupled movement and bioenergetics model to explore the spawning migration of anchovy in the Bay of Biscay. Ecol. Model. 313, $212-$ 222. doi:10.1016/j.ecolmodel.2015.06.036

Preisendorfer, R., 1988. Principal Component Analysis in meteorology and oceanography. Elsevier, Amsterdam, Netherlands.

R Core Team, 2016. R: A language and environment for statistical computing. R Foundation for Statistical Computing, Vienna, Austria.

Reiss, M.J., 1991. The Allometry of Growth and Reproduction. Cambridge University Press.

Saraux, C., Fromentin, J.-M., Bigot, J.-L., Bourdeix, J.-H., Morfin, M., Roos, D., Van Beveren, E., Bez, N., 2014. Spatial Structure and Distribution of Small Pelagic Fish in the Northwestern Mediterranean Sea. Plos One 9, e111211. doi:10.1371/journal.pone.0111211

Schaefer, K.M., 1986. Lethal Temperatures and the Effect of Temperature Change on Volitional Swimming Speeds of Chub Mackerel, Scomber japonicus. Copeia 1986, 39. doi:10.2307/1444885 
Shin, Y., Rochet, M., Jennings, S., Field, J., Gislason, H., 2005. Using size-based indicators to evaluate the ecosystem effects of fishing. ICES J. Mar. Sci. 62, 384-396. doi:10.1016/j.icesjms.2005.01.004

Simard, Y., Marcotte, D., Naraghi, K., 2003. Three-dimensional acoustic mapping and simulation of krill distribution in the Saguenay St. Lawrence Marine Park whale feeding ground. Aquat Living Resour 16, 137-144.

Simmonds, E.J., MacLennan, D.N., 2005. Fisheries Acoustics. Theory and Practice. Blackwell publishing, Oxford, UK.

Spitz, J., Cherel, Y., Bertin, S., Kiszka, J., Dewez, A., Ridoux, V., 2011. Prey preferences among the community of deep-diving odontocetes from the Bay of Biscay, Northeast Atlantic. Deep Sea Res. Part Oceanogr. Res. Pap. 58, 273-282. doi:10.1016/j.dsr.2010.12.009

Thioulouse, J., Simier, M., Chessel, D., 2004. Simultaneous analysis of a sequence of paired ecological tables. Ecology 85, 272-283.

Vaz, S., Carpentier, A., Coppin, F., 2007. Eastern English Channel fish assemblages: measuring the structuring effect of habitats on distinct sub-communities. ICES J. Mar. Sci. 64, 271-287. doi:10.1093/icesjms/fs1031

Vaz, S., Petitgas, P., 2002. Study of the bay of Biscay anchovy population dynamics using spatialised age-specific matrix models. ICES CM 20.

Villamor, B., Abaunza, P., Petitgas, P., Massé, J., Uriarte, A., 2007. Bay of Biscay anchovy: a resource in crisis. ICES Insight 9-10.

Wollenberg, A.L. van den, 1977. Redundancy analysis an alternative for canonical correlation analysis. Psychometrika 42, 207-219. doi:10.1007/BF02294050

Whaley, S., Burd, J., Robertson, B., 2007. Using estuarine landscape structure to model distribution patterns in nekton communities and in juveniles of fishery species. Mar Ecol Prog Ser 330, 99.

Woillez, M., Petitgas, P., Huret, M., Struski, C., Léger, F., 2010. Statistical monitoring of spatial 
patterns of environmental indices for integrated ecosystem assessment: Application to the Bay of Biscay pelagic zone. Prog. Oceanogr. 87, 83-93.

695 


\section{Figures}

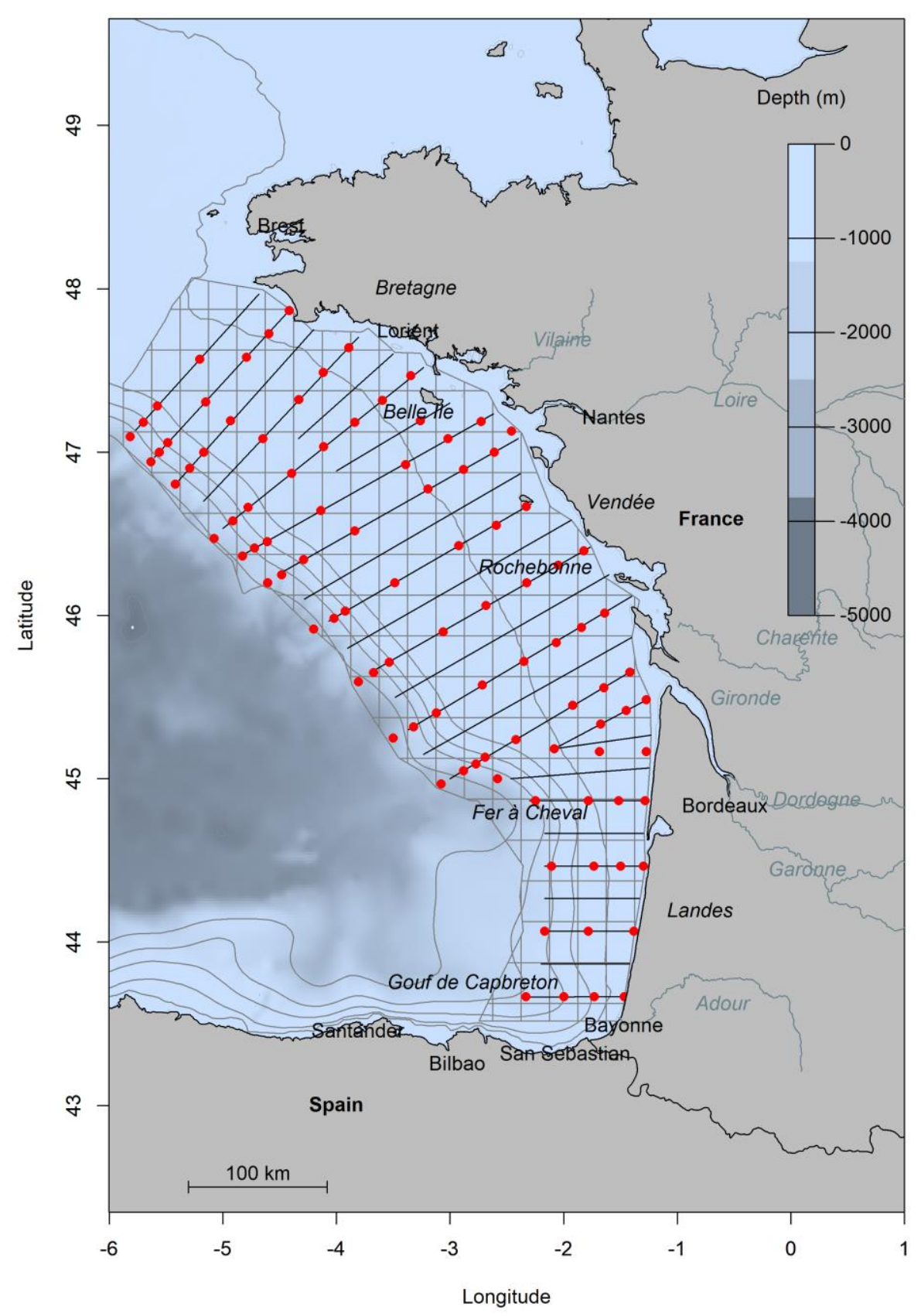

Figure 1. PELGAS survey sampling scheme. Solid lines: systematic line transects, red dots: hydrobiology stations. Light grey grid: block averaging grid. Light grey lines: 100, 200, 300, 400, $500 \mathrm{~m}$ isobaths. 

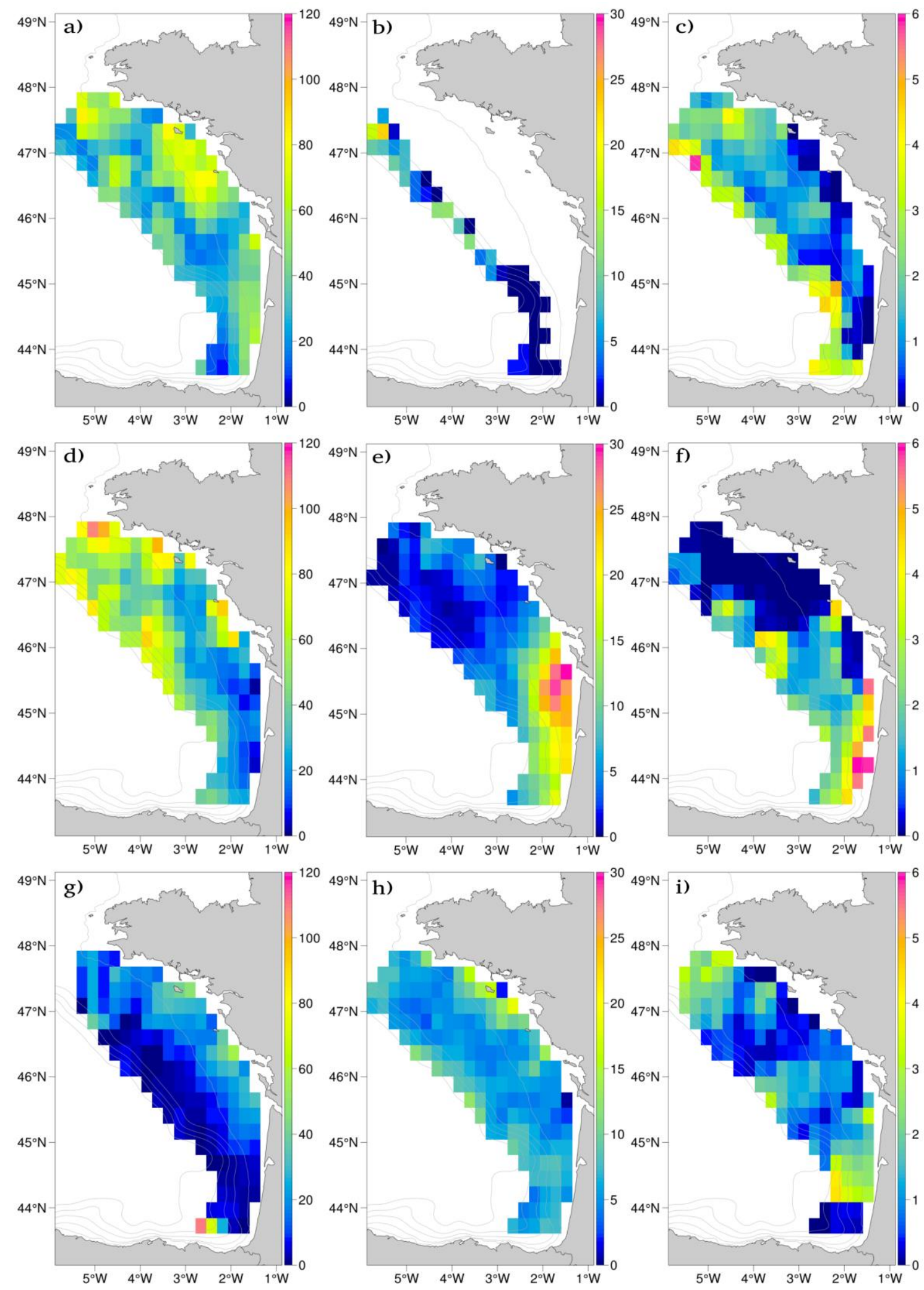

Figure 2a. Average maps of small pelagic fish biomass (in tons): a) Sardina pilchardus, b) Capros aper, c)

Micromesistius poutassou, d) Scomber scombrus, e) Engraulis encrasicolus, f) Scomber colias, g) Sprattus sprattus, h) Trachurus trachurus, i) Trachurus mediterraneus. Species common names and abbreviations can be found in Table 1. PELGAS survey data, 2000-2015. Grid cell size: $0.25^{\circ} \times 0.25^{\circ}$. A white cell indicates zero occurrence over the series. Light grey lines: 100, 200, 300, 400, $500 \mathrm{~m}$ isobaths. 

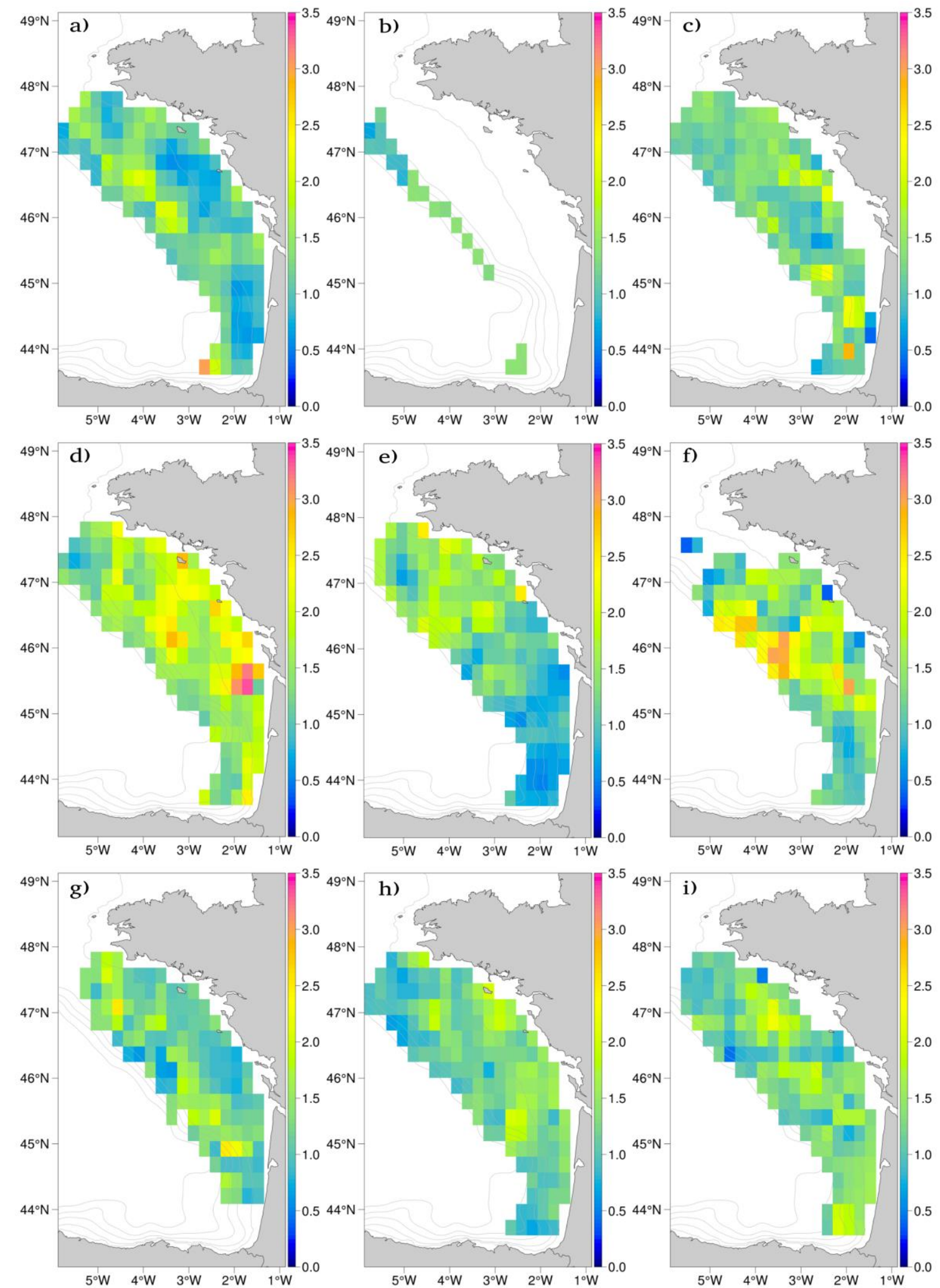

Figure 2b. Maps of small pelagic fish biomass coefficient of variation: a) Sardina pilchardus, b) Capros aper,

c) Micromesistius poutassou, d) Scomber scombrus, e) Engraulis encrasicolus, f) Scomber colias, g) Sprattus sprattus, h) Trachurus trachurus, i) Trachurus mediterraneus. Species common names and abbreviations can be found in Table 1. PELGAS survey data, 2000-2015. Grid cell size: $0.25^{\circ} \mathrm{x} 0.25^{\circ}$. A white cell indicates zero occurrence over the series. Light grey lines: 100, 200, 300, 400, 500 m isobaths. 


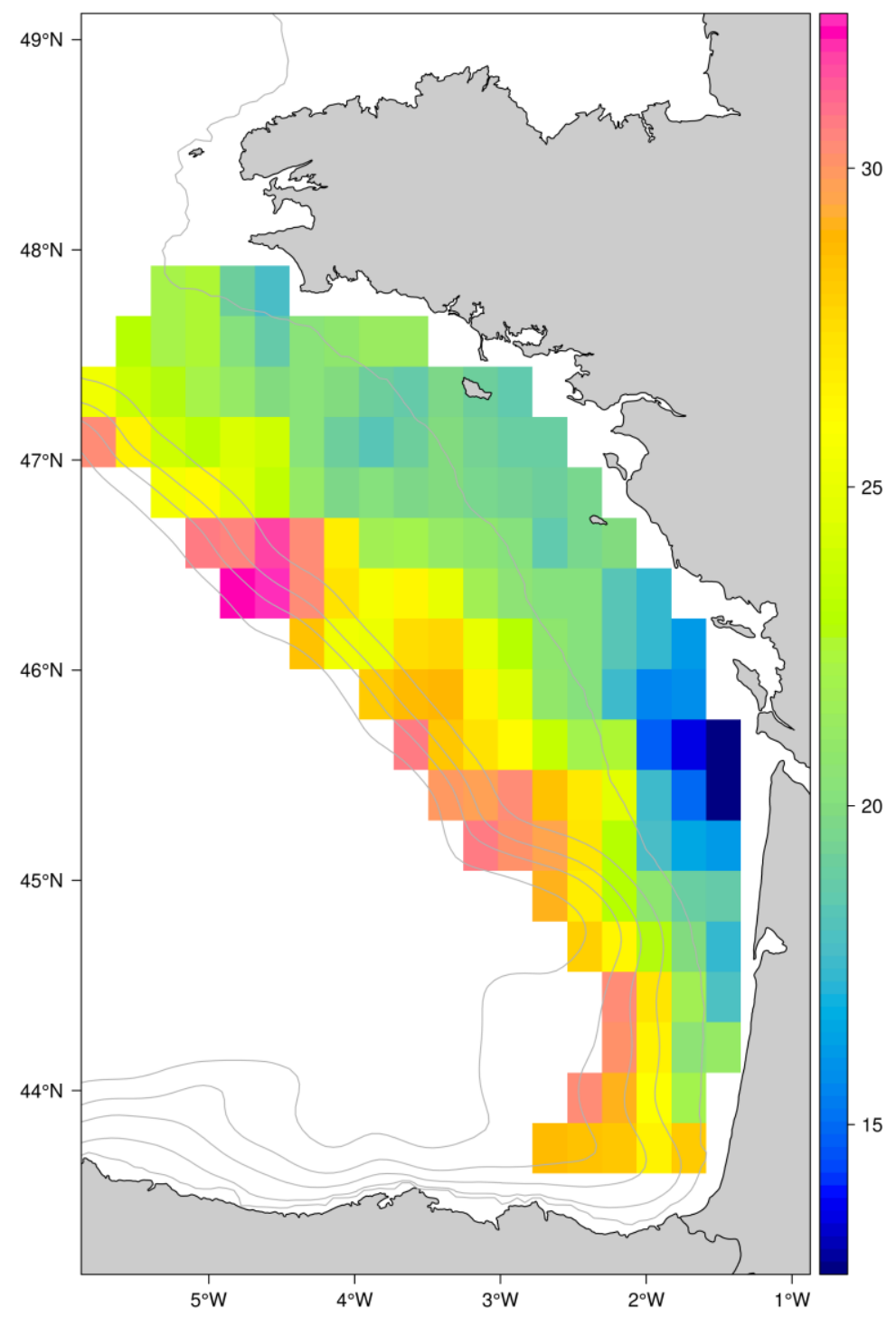

Figure 3. Average map of small pelagic fish mean lengths $(\mathrm{cm})$, weighted by biomass. PELGAS survey data, 2000-2015. Grid cell size: $0.25^{\circ} \times 0.25^{\circ}$. Light grey lines: $100,200,300,400,500 \mathrm{~m}$ isobaths. 


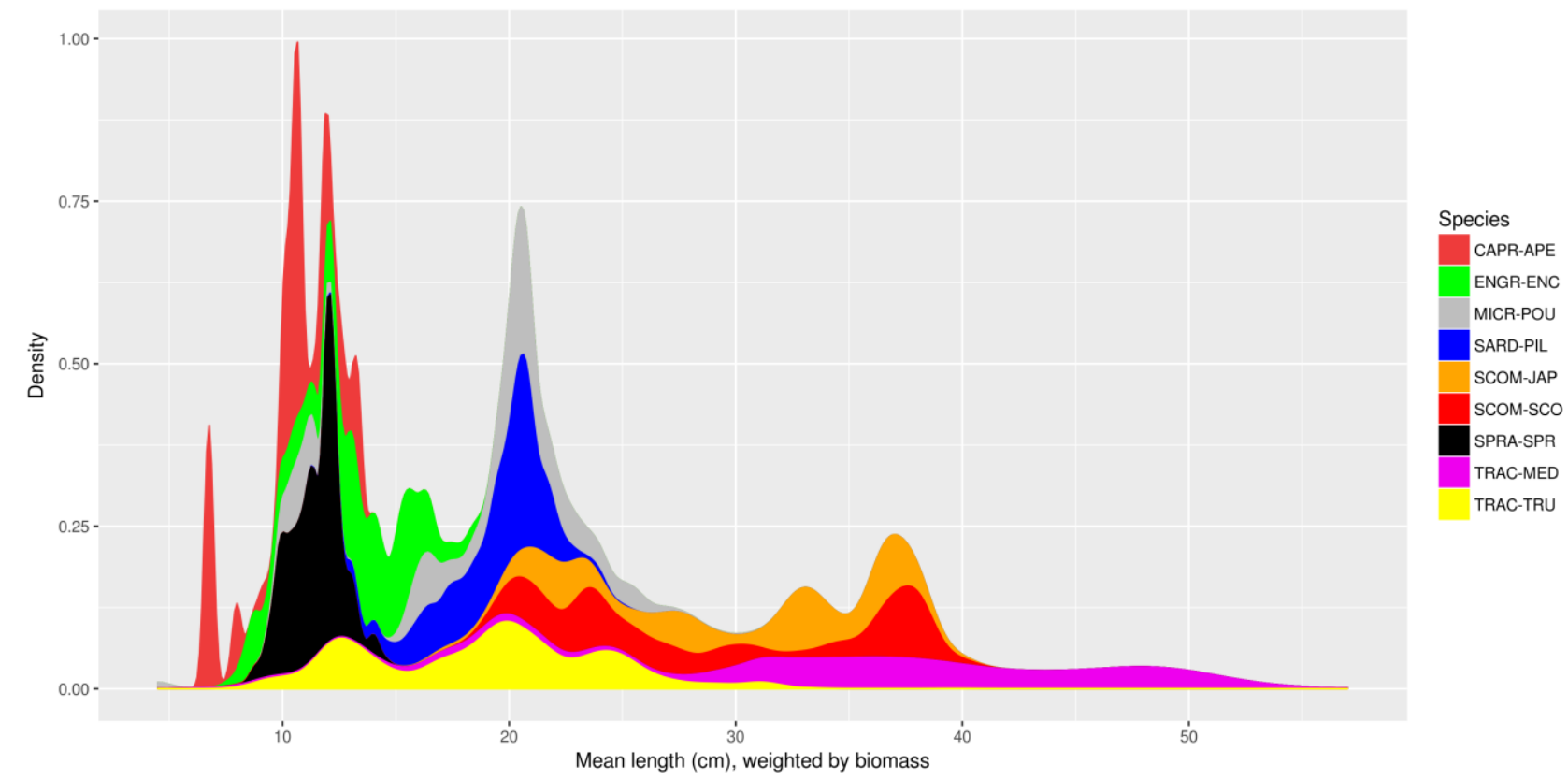

730 Figure 4. Mean lengths distributions of small pelagic fish species, weighted by biomass. PELGAS survey data, 2000-2015. Species common names and abbreviations can be found in Table 1. 

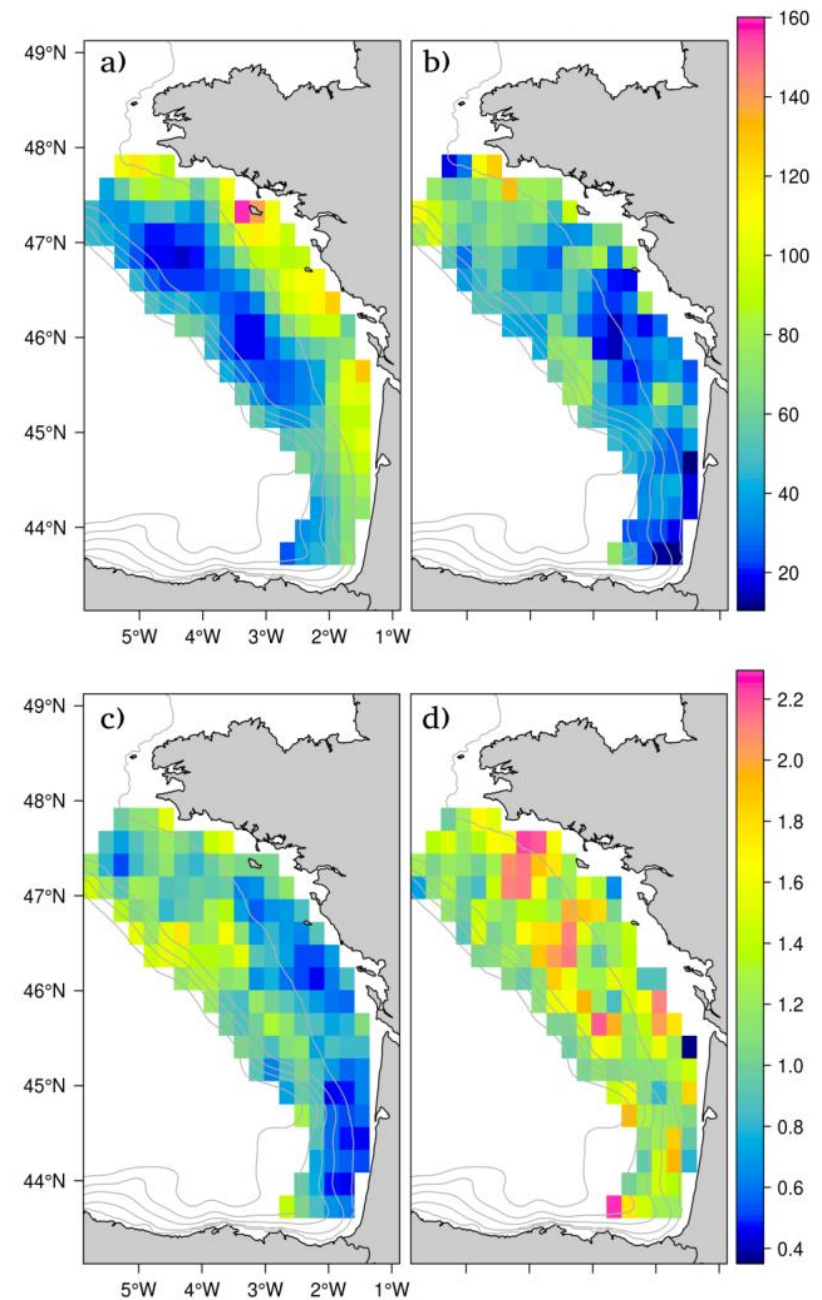

Figure 5. Maps of mean and coefficient of variation (CV) of small pelagic fish biomass for all species. Upper row: maps of average biomass in: a) deeper $(>30 \mathrm{~m})$, and b) surface $(0-30 \mathrm{~m})$ depth layers. Lower row: maps of biomass CV in: c) deeper (>30 m), and d) surface (0-30m) depth layers. PELGAS survey data, 2000-2015.

750 Grid cell size: $0.25^{\circ} \times 0.25^{\circ}$. Light grey lines: $100,200,300,400,500 \mathrm{~m}$ isobaths. 

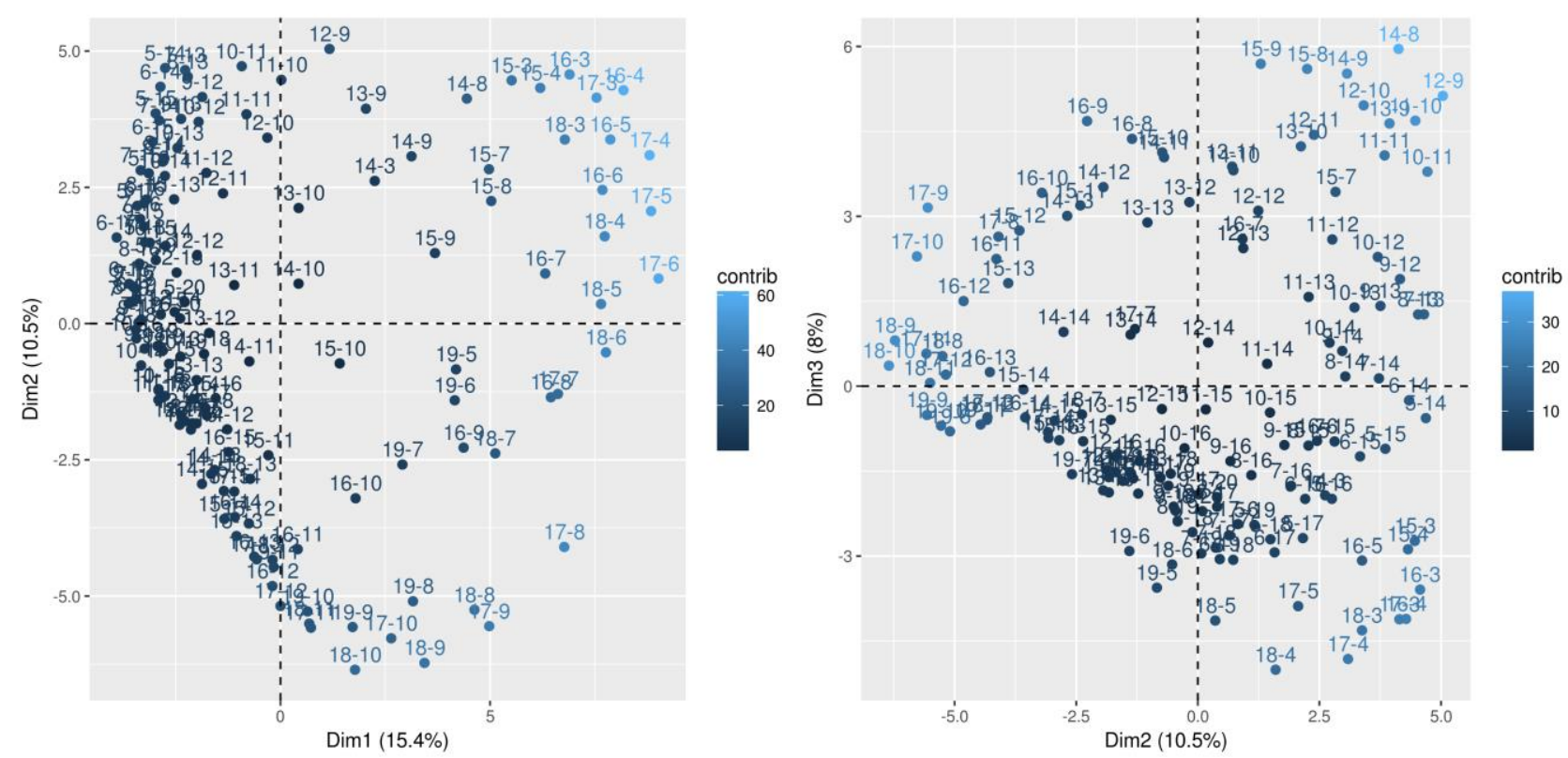

Figure 6. Projections of map cells (dots) on the factorial planes defined by the first three components of the Multiple Factor Analysis (MFA) performed on small pelagic fish biomass maps collected during the PELGAS survey between 2000-2015. Left pane: factorial plane defined by MFA components 1 (Dim.1) and 2 (Dim.3).

755 Right pane: factorial plane defined by MFA components 2 (Dim.2) and 3 (Dim.3). The percentage of total variance explained by each MFA component is indicated between brackets. Map cells are labelled with their cell name, colour scales represent the cell contribution (contrib in \%) to the MFA planes. PELGAS survey fish biomass data, 2000-2015. 


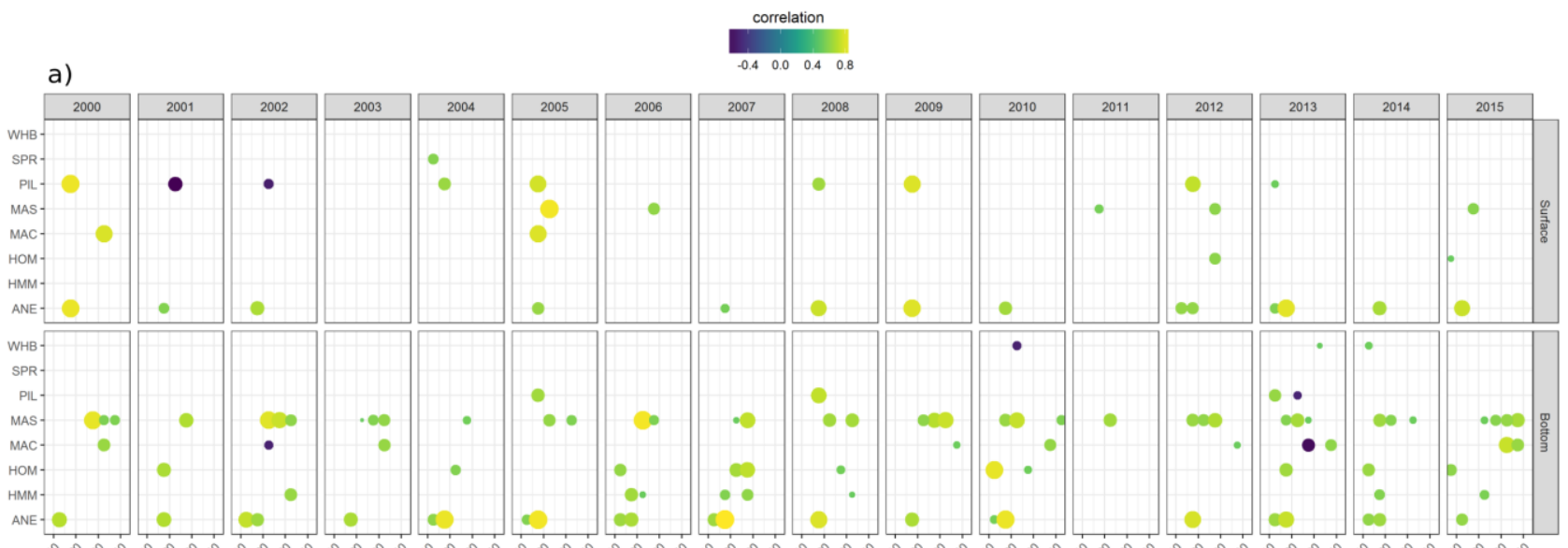

b)

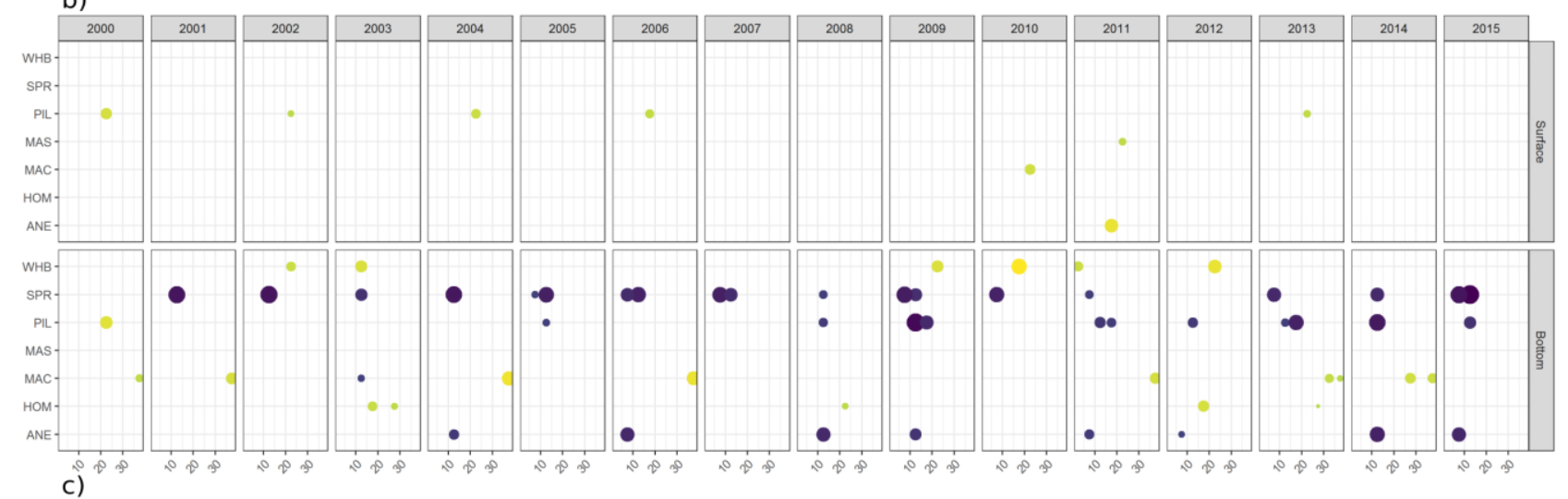

C)

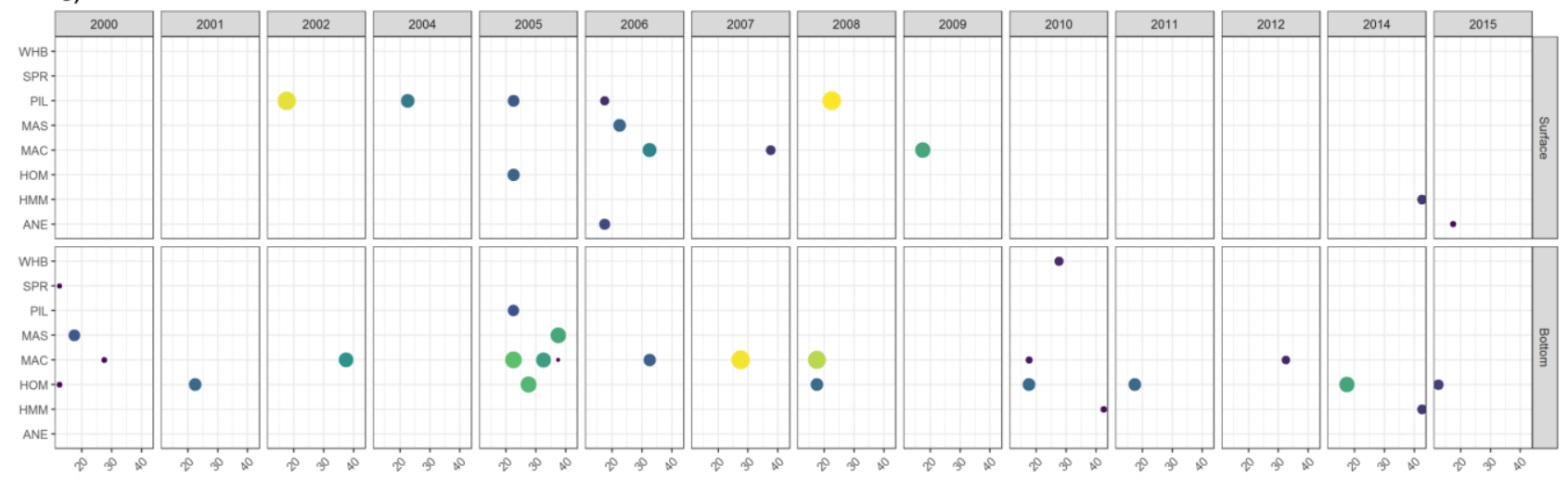

760 Figure 7. Small pelagic fish biomass variables contributing most to the first 3 components of the Multiple

Factor Analysis (MFA) performed on PELGAS data. Dots: significant correlations (absolute value >=0.5) between small pelagic fish biomass per species (y-axis), length-class (x-axis), depth layers (rows) and year (columns) and: a) MFA component 1, b) MFA component 2, and c) MFA component 3. Dot size and colour is proportional to the correlation value. Upper row: fish observed in the 0-30 m depth layer outside shallow

765 (<50m depth) areas (Surface). Lower row: fish observed in below $30 \mathrm{~m}$ depth and/or in shallow ( $<50 \mathrm{~m}$ depth) areas (Bottom). Midpoints of $5 \mathrm{~cm}$ width size categories are represented on the bottom x-axis. Species common names and abbreviations can be found in Table 1 . 

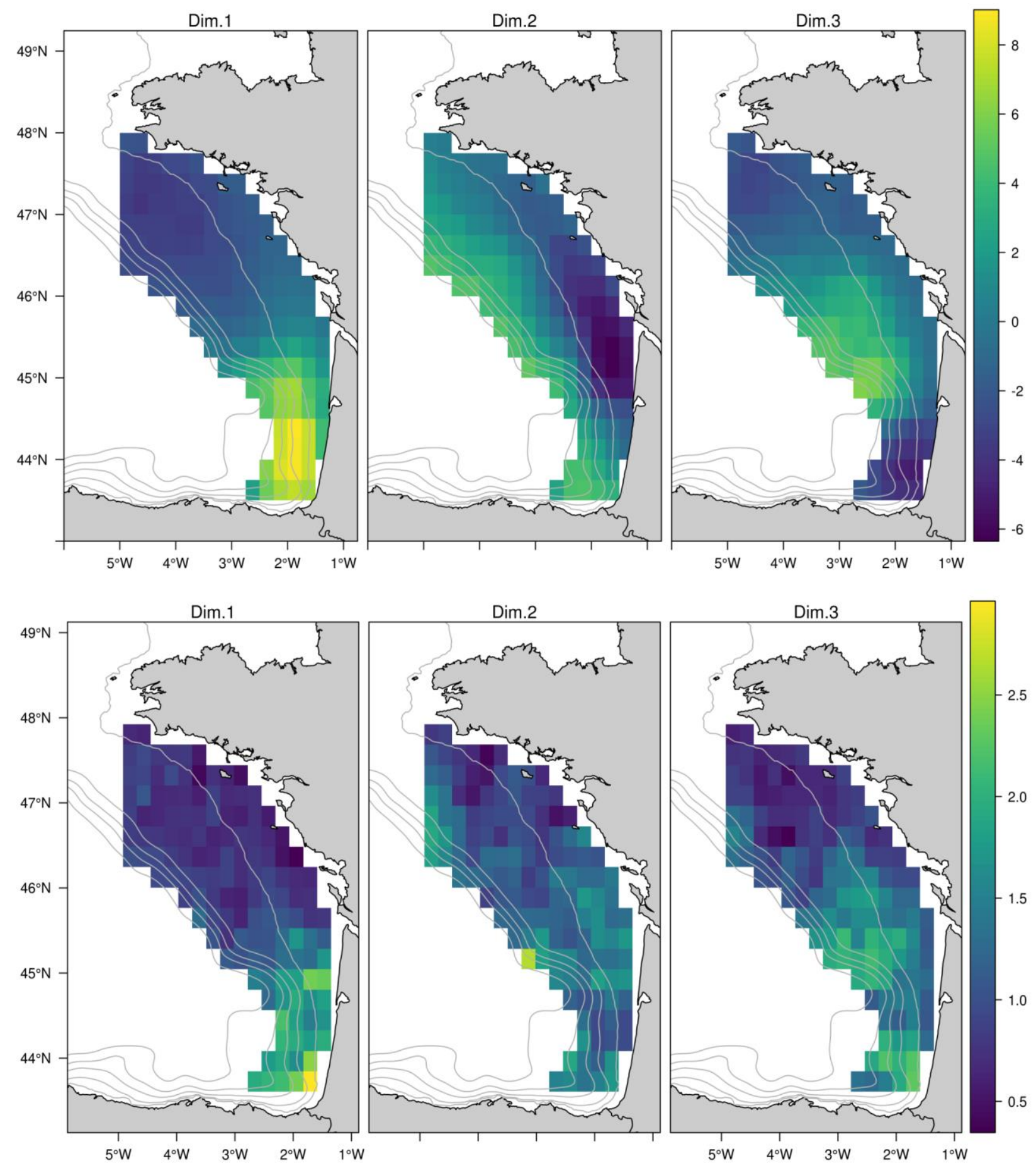

Figure 8. Upper row: maps of mean individuals (map cells) coordinates on the Multiple Factor Analysis (MFA)

axes 1 to 3 (Dim.1, 2, 3) performed on PELGAS small pelagic fish biomass. Lower row: maps of inter-annual fish biomass inertia on MFA axes 1 to 3 (Dim.1, 2, 3). PELGAS survey fish biomass data, 2000-2015. Grid cell size: $0.25^{\circ} \times 0.25^{\circ}$. Light grey lines: $100,200,300,400,500 \mathrm{~m}$ isobaths. 

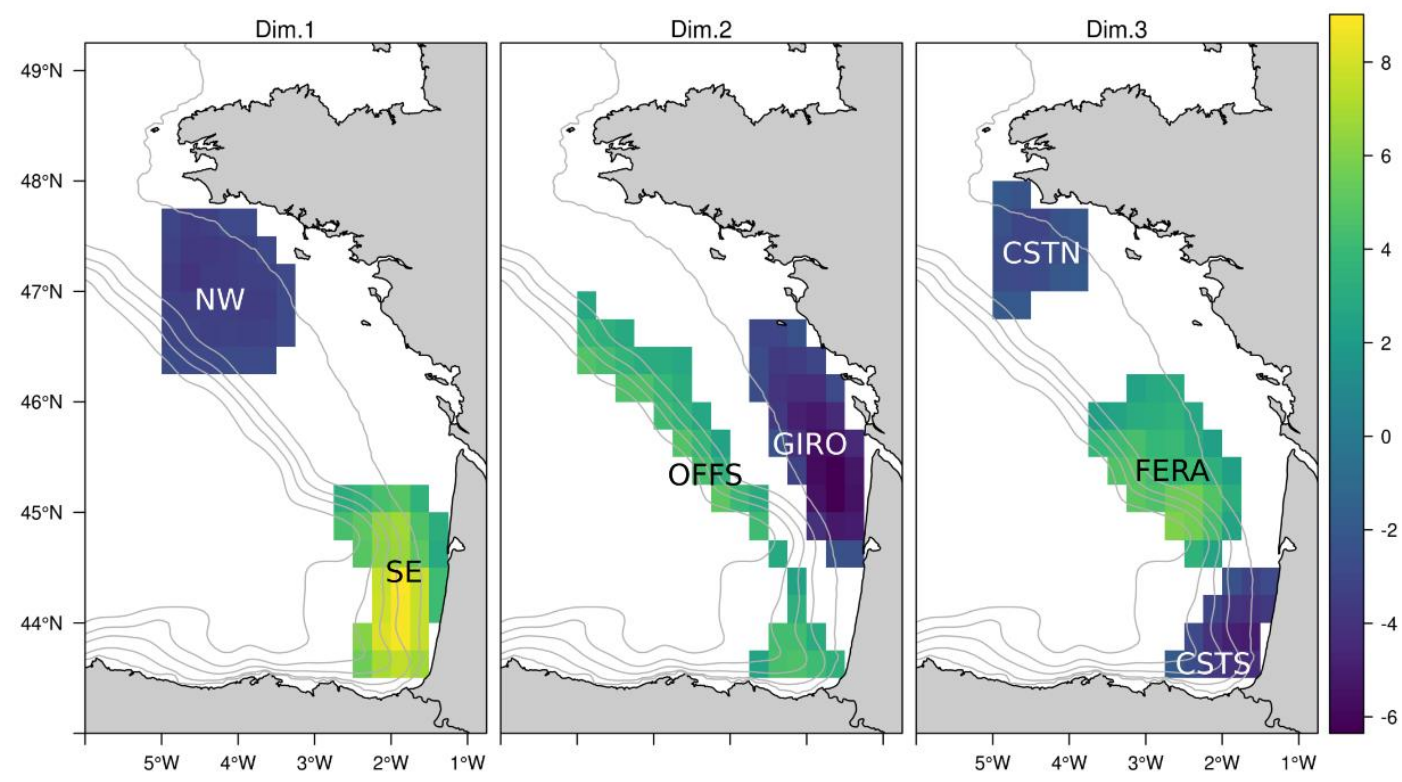

775 Figure 9. Characteristic areas occupied by typical small pelagic fish communities observed in springtime in the Bay of Biscay. The figure shows maps of mean individuals (map cells) coordinates on the Multiple Factor Analysis (MFA) axes 1 to 3 (Dim.1, 2, 3), whose contribution to MFA components is higher than the coordinate median values on the respective axes. NW: north-west, SE: south-east MFA1 characteristic area. GIRO: Gironde estuary, OFFS: shelf break MFA2 characteristic areas. CSTN: coastal north, CSTS: coastal south, FERA: Fer à Cheval MFA3 characteristic areas. PELGAS survey fish biomass data, 2000-2015. Grid cell size: $0.25^{\circ} \times 0.25^{\circ}$. Light grey lines: $100,200,300,400,500 \mathrm{~m}$ isobaths. 


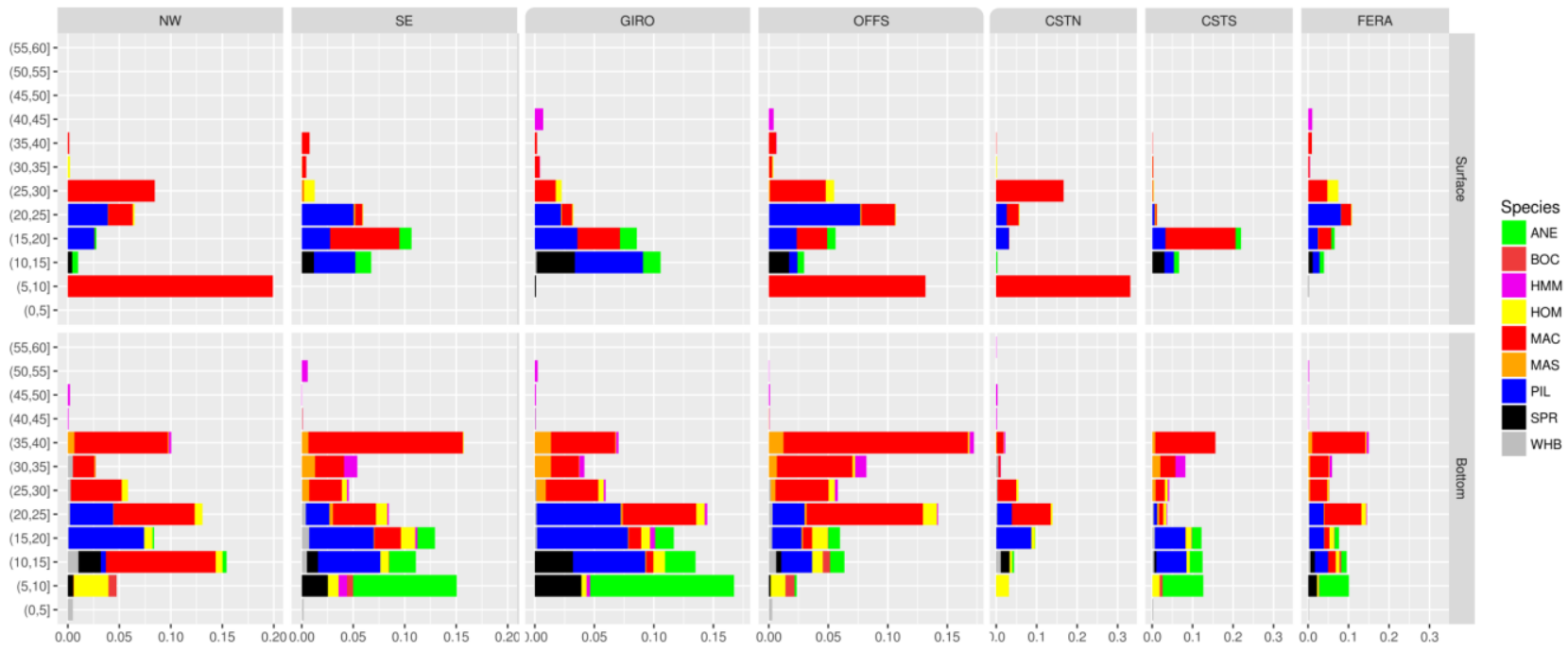

Figure 10. Relative mean composition (\% of biomass, $\mathrm{x}$-axis) by $5 \mathrm{~cm}$ size class ( $\mathrm{y}$-axis) of typical small pelagic fish communities encountered in the Bay of Biscay characteristic areas. NW: north-west, SE: south-east MFA1

785 characteristic area. GIRO: Gironde estuary, OFFS: shelf break MFA2 characteristic areas. CSTN: coastal north, CSTS: coastal south, FERA: Fer à Cheval MFA3 characteristic areas. Species common names and abbreviations can be found in Table 1. PELGAS survey data, 2000-2015. 

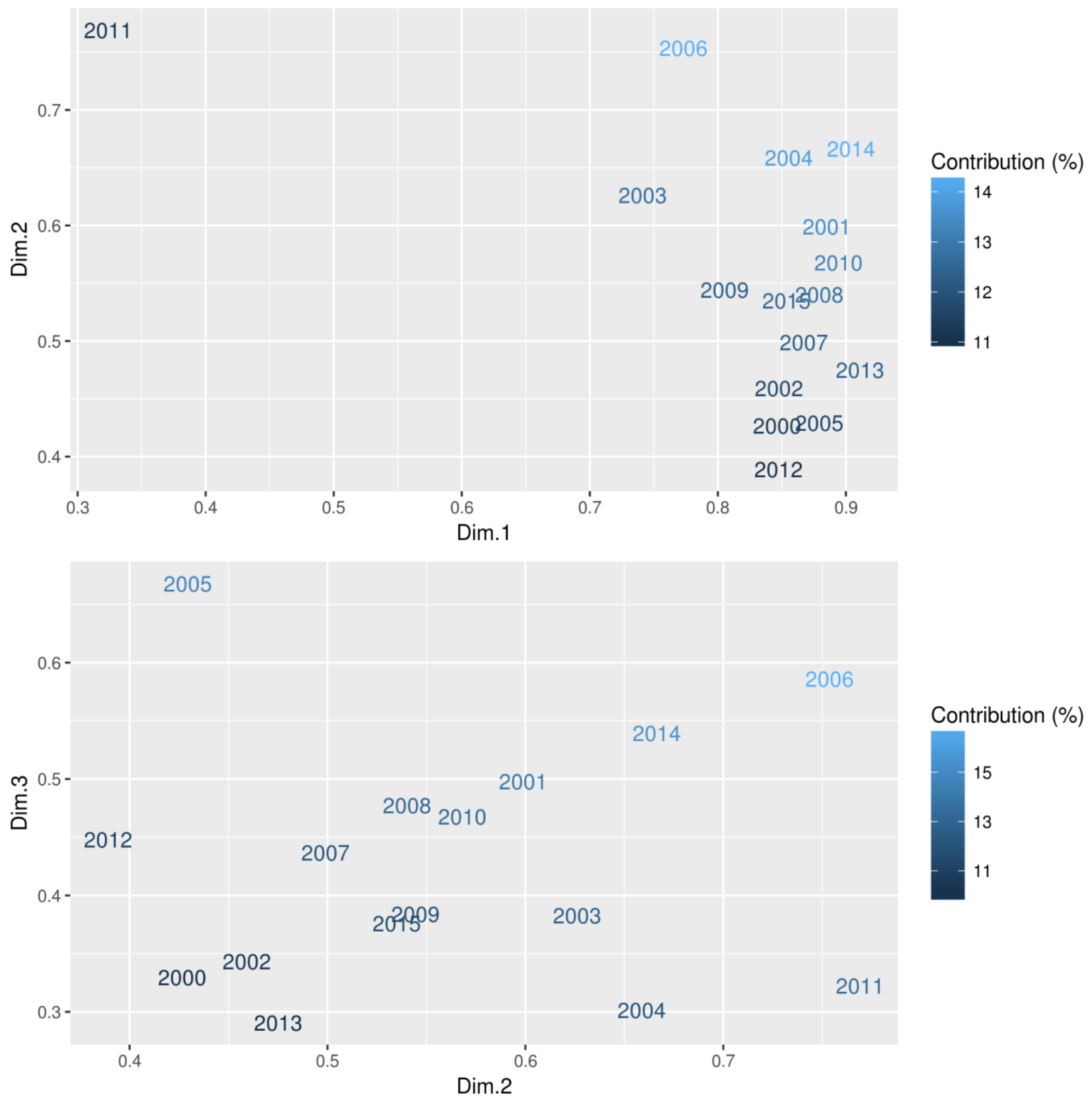

Figure 11. Coordinates and contributions of groups (years) on the first 3 components (Dim.1, 2, 3) of the

790 Multiple Factor Analysis (MFA) of fish biomass maps. Colour scales represent the cell contribution (contrib in \%) to the MFA planes. PELGAS survey fish biomass data, 2000-2015. 

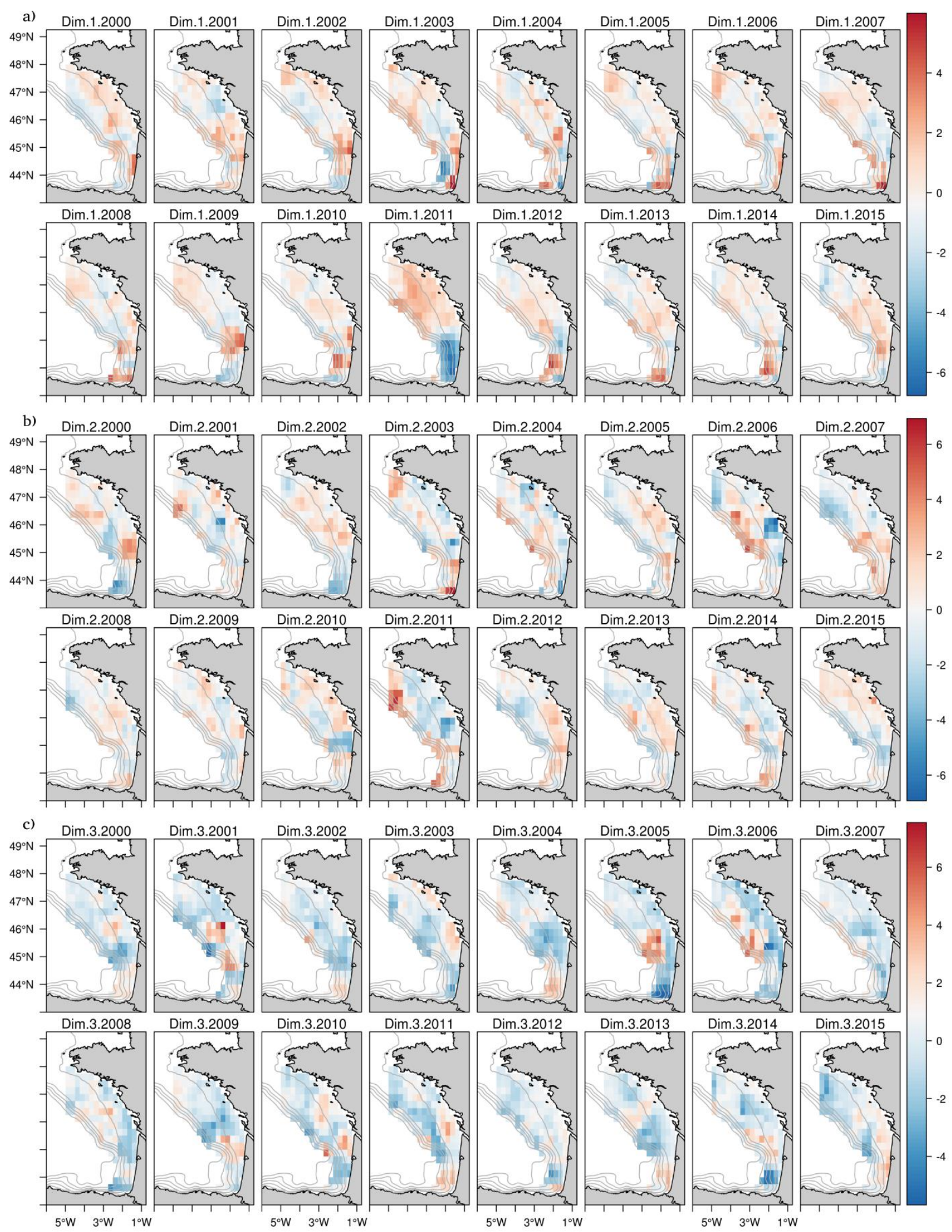

Figure 12. Maps of anomalies of partial individuals (map cells:year pairs) coordinates on: a) Multiple Factor Analysis (MFA) axis 1 (Dim.1); b) MFA axis 2 (Dim.2); c) MFA axis 3 (Dim.3). PELGAS survey fish biomass data, 2000-2015. Grid cell size: $0.25^{\circ} \times 0.25^{\circ}$. Light grey lines: $100,200,300,400,500 \mathrm{~m}$ isobaths. 

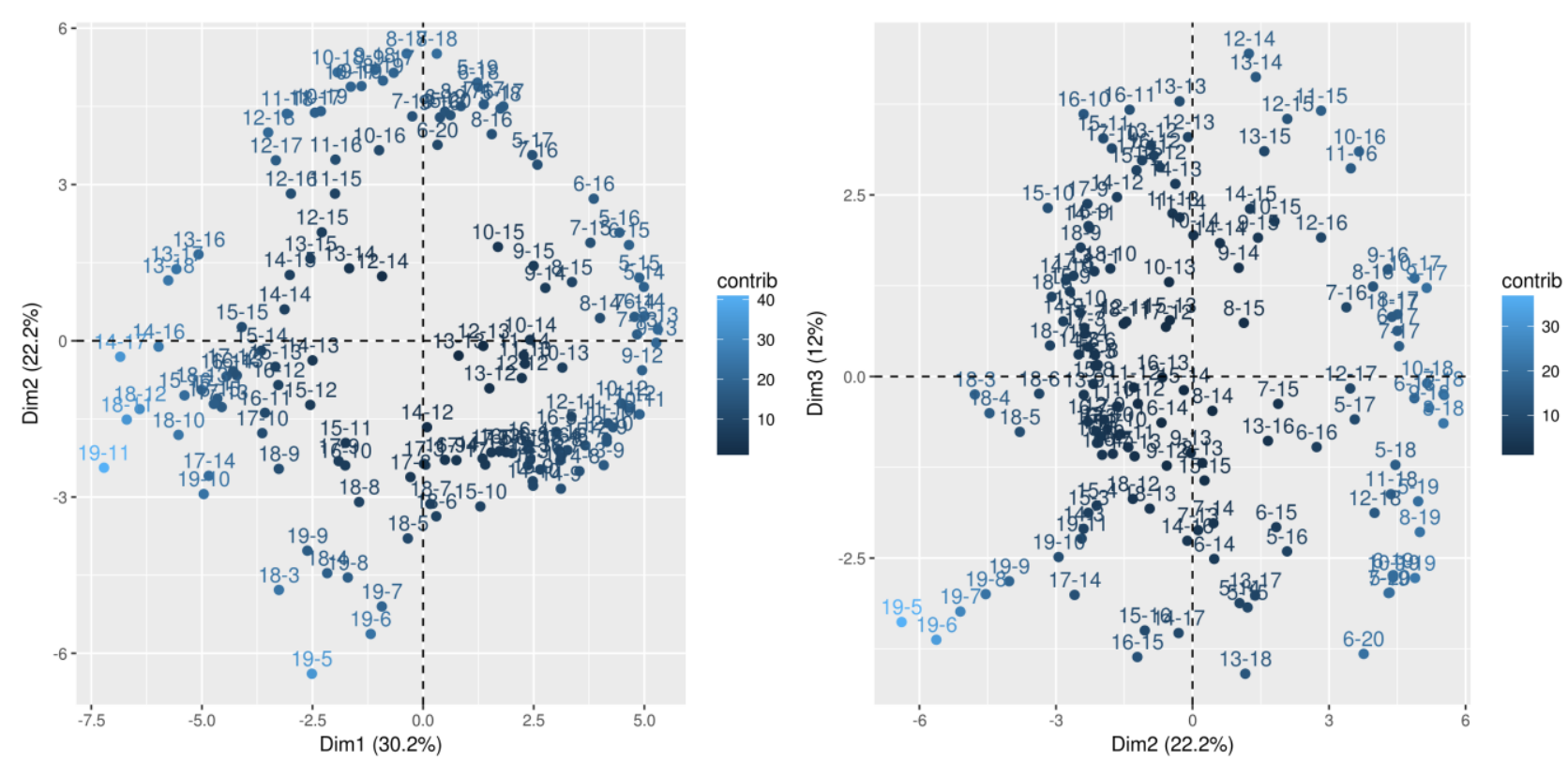

Figure 13. Projections of map cells (dots) on the factorial planes defined by the first three components of the Multiple Factor Analysis (MFA) performed on PELGAS hydrological indices maps. Left pane: factorial plane

800 defined by MFA components 1 (Dim.1) and 2 (Dim.3). The percentage of total variance explained by each MFA component is indicated between brackets. Right pane: factorial plane defined by MFA components 2 (Dim.2) and 3 (Dim.3). Map cells are labelled with their cell name, colour scales represent the cell contribution (contrib in \%) to the MFA planes. PELGAS survey hydrology data, 2000-2015. 

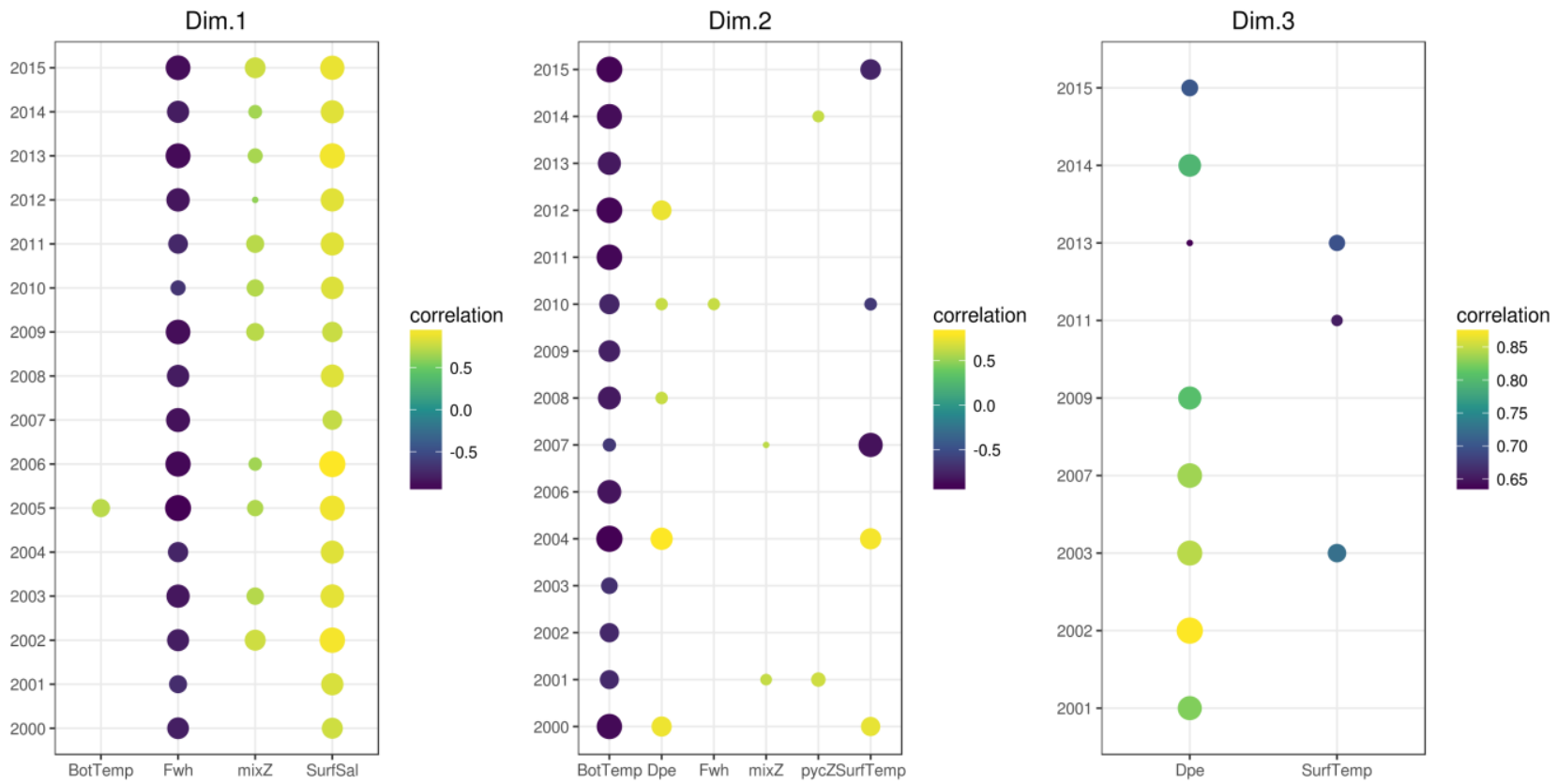

805 Figure 14. Hydrology variables contributing most to the first 3 components of the Multiple Factor Analysis (MFA) performed on PELGAS data. Dots: significant correlations (absolute value $>=0.6$ ) between the hydrology MFA components 1 (Dim.1), 2 (Dim.2), and 3 (Dim.3) and the hydrological indices (x-axis): BotTemp: bottom temperature, SurfTemp: surface temperature, Fwh: equivalent freshwater height, mixZ: mixed layer maximum depth, SurfSal: surface salinity, pycZ: pycnocline depth, Dpe: deficit of potential 810 energy. Dot size and colour is proportional to the correlation value. PELGAS survey hydrology data, 20002015. 

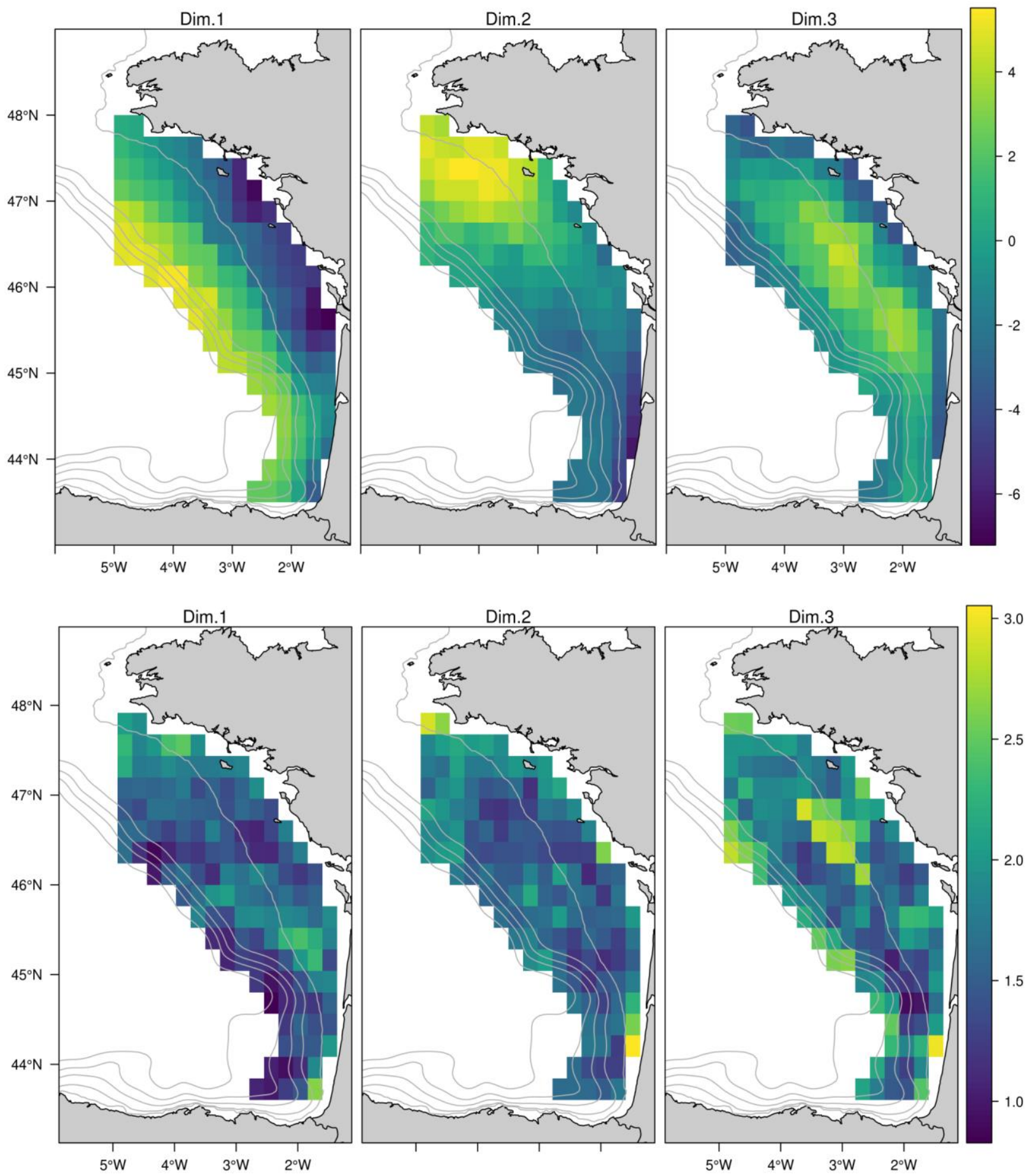

Figure 15. Upper row: maps of mean individuals (map cells) coordinates on Multiple Factor Analysis (MFA) axes 1 to 3 (Dim.1 to Dim.3). Lower row: maps of inter-annual inertia on MFA axes 1 to 3. PELGAS hydrology 815 data, 2000-2015. Grid cell size: $0.25^{\circ} \times 0.25^{\circ}$. Light grey lines: $100,200,300,400,500 \mathrm{~m}$ isobaths. 
a)

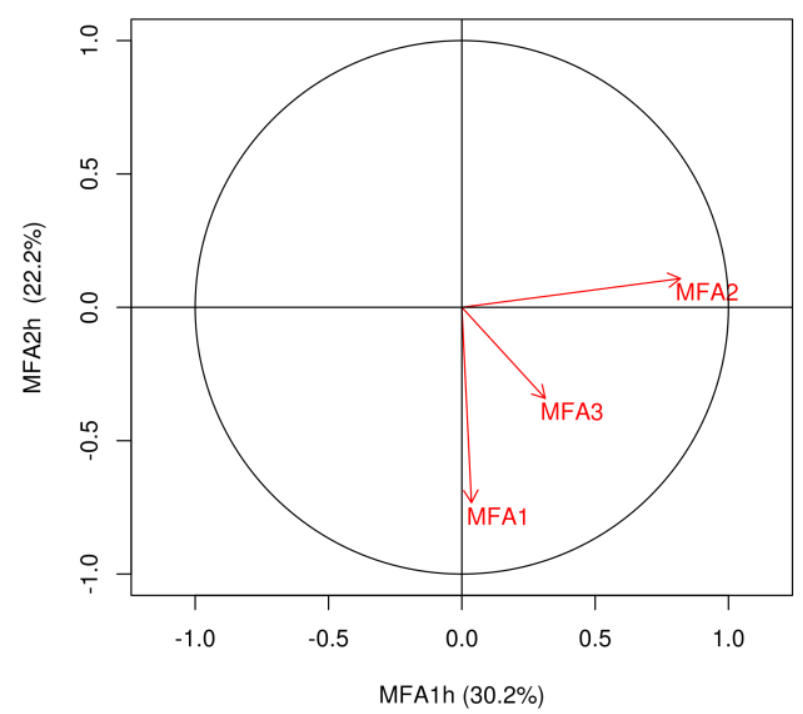

b)

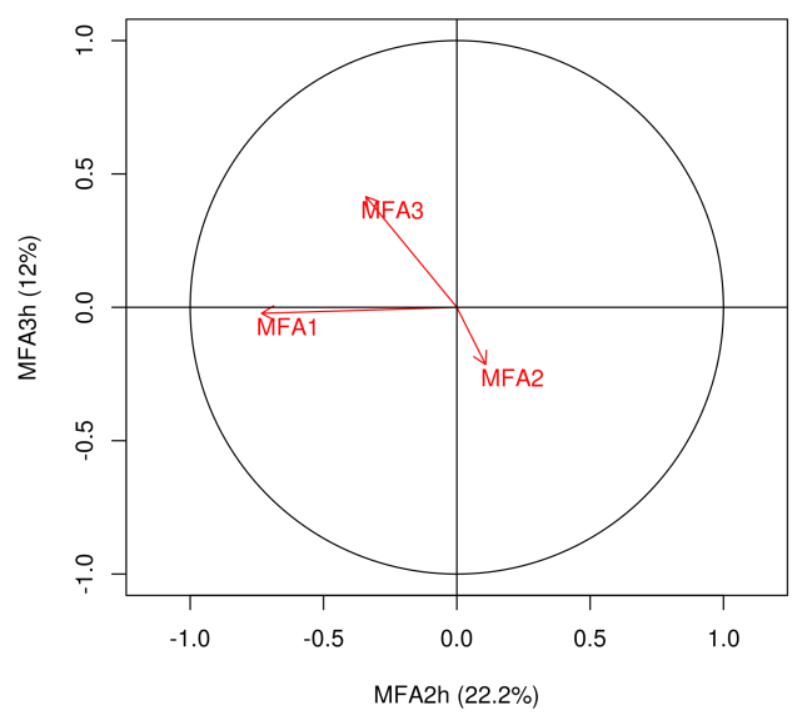

Figure 16. Projection of the first 3 components of the Multiple Factor Analysis (MFA1-3) on fish biomass maps onto the factorial planes of the MFA on hydrology maps (MFAh) defined by: a) MFAh axes 1 and 2, b) MFAh axes 2 and 3. The percentage of total variance explained by each MFA component is indicated between 820 brackets. PELGAS survey data, 2000-2015. 


\section{Tables}

Table 1. Small pelagic fish names and abbreviations.

\begin{tabular}{|c|l|l|l|}
\hline Code & Scientific name & English name & Author \\
\hline \hline PIL & Sardina pilchardus & European sardine & Walbaum, 1792 \\
\hline \hline SPR & Sprattus sprattus & European sprat & Linnaeus, 1758 \\
\hline \hline ANE & Engraulis encrasicolus & European anchovy & Linnaeus, 1758 \\
\hline \hline WHB & Micromesistius poutassou & Blue whiting & Risso, 1827 \\
\hline BOC & Capros aper & Boarfish & Linnaeus, 1758 \\
\hline \hline HOM & Trachurus trachurus & Atlantic horse mackerel & Linnaeus, 1758 \\
\hline \hline HMM & Trachurus mediterraneus & Mediterranean horse mackerel & Steindachner, 1868 \\
\hline \hline MAS & Scomber colias & Atlantic chub mackerel & Gmelin, 1789 \\
\hline \hline MAC & Scomber scombrus & Atlantic mackerel & Linnaeus 1758 \\
\hline
\end{tabular}


Table 2. Summary statistics of variables (first row) defining the first 2 components of the hydrology Multiple Factor Analysis (MFA), in the characteristic areas (second row) of small pelagic fish communities derived from the MFA of fish biomass maps. Student's t statistic and p-value refer to the test for significant differences in variables means between areas.

\begin{tabular}{|l|c||c|c|c|}
\hline Variable & \multicolumn{3}{|c|}{ Bottom temperature $\left({ }^{\circ} \mathrm{C}\right)$} & Surface salinity (PSU) \\
\hline \hline Area & North-West & South-East & Gironde & Offshore \\
\hline \hline Minimum & 10.13 & 10.36 & 30.23 & 32.48 \\
\hline $25 \%$ quantile & 11.15 & 11.91 & 33.71 & 35.13 \\
\hline \hline Median & 11.5 & 12.17 & 34.15 & 35.45 \\
\hline \hline Mean & 11.44 & 12.18 & 34.1 & 35.29 \\
\hline \hline $75 \%$ quantile & 11.79 & 12.34 & 34.62 & 35.6 \\
\hline Maximum & 12.57 & 14.53 & 35.61 & 35.77 \\
\hline \hline Standard deviation & 0.47 & 0.44 & 0.76 & 0.44 \\
\hline \hline Student's t & \multicolumn{2}{|c|}{-653.76} & -783.19 \\
\hline \hline Student's t test p-value & $<2.2 \mathrm{e}-16$ & \multicolumn{2}{|c|}{$<2.2 \mathrm{e}-16$} \\
\hline
\end{tabular}


